\title{
Molecular dynamics of fentanyl bound to $\mu$-opioid receptor
}

\author{
Piotr F. J. Lipiński ${ }^{1}$ - Małgorzata Jarończyk ${ }^{2}$ • Jan Cz. Dobrowolski ${ }^{2}$ • Joanna Sadlej ${ }^{3}$
}

Received: 24 August 2018 / Accepted: 21 March 2019 / Published online: 3 May 2019

(C) The Author(s) 2019

\begin{abstract}
The molecular dynamics simulations of fentanyl complexed with the $\mu$-opioid receptor $(\mu \mathrm{OR})$ were studied using both inactive 4DKL and active 5C1M opioid receptor crystal structures. Analogous simulations in morphine with or without a ligand were done for comparison. Simulations of the inactive states were carried out in the absence and presence of the $\mathrm{Na}^{+}$ion. The obtained fentanyl's binding mode agrees with some of the mutagenesis data, and it overlaps with that of morphine only to a minor extent. Notably, fentanyl stabilizes different rotameric states of $\operatorname{Trp} 293^{6.48}$ than observed for morphine or unliganded receptor. Another difference is tighter arrangement of the interaction between Asp147 $7^{3.32}$ and Tyr326 $6^{7.43}$ (a link between helices TM3 and TM7) in the presence of fentanyl. Principal component analysis reveals differences in the trajectories dependent on the ligand bound. The differences found could be linked to ligand-dependent efficacy with respect to receptor intracellular signaling events.
\end{abstract}

Keywords $\mu$-opioid receptor · Molecular dynamics $\cdot$ Fentanyl $\cdot$ Morphine $\cdot$ "Fentanyl death"

\section{Introduction}

The $\mu$-opioid receptor $(\mu \mathrm{OR})$ agonists are among the most effective medicines for the treatment of severe pain [1]. Although they are highly potent, there is still a field open for innovation, since opioids are not devoid of unwanted and possibly dangerous side effects (e.g., constipation, nausea, respiratory depression, tolerance, dependence, etc.) [2-4].

Electronic supplementary material The online version of this article (https://doi.org/10.1007/s00894-019-3999-2) contains supplementary material, which is available to authorized users.

Piotr F. J. Lipiński

plipinski@imdik.pan.pl

Joanna Sadlej

j.sadlej@uksw.edu.pl

Małgorzata Jarończyk

m.jaronczyk@nil.gov.pl

Jan Cz. Dobrowolski

j.dobrowolski@nil.gov.pl

1 Mossakowski Medical Research Centre Polish Academy of Sciences, 5 Pawińskiego-Street, 02-106 Warsaw, Poland

2 National Medicines Institute, 30/34 Chełmska-Str, 00-725 Warsaw, Poland

3 Faculty of Mathematics and Natural Sciences, University of Cardinal Stefan Wyszyński, 1/3 Wóycickiego-Street, 01-938 Warsaw, Poland
The modern medicine needs novel (safer and more potent) analgesics. With the major progress in the field of structural biology of $\mu \mathrm{OR}$, these needs are more likely to be answered in the near future. As we now have three $\mu \mathrm{OR}$ crystal structures available [9-11], they provide us with an unprecedented insight into $\mu \mathrm{OR}$ function and interaction with ligands. This has already brought about (and is certainly going to keep on doing so) practical advancements like the discovery of novel active compounds [5-11].

The rational search for new analgesic substances benefits from taking into account as much as it is possible to know about the currently known drugs. Opioid receptor ligands include several classes of quite distinct molecules (e.g., opium alkaloids and their derivatives, morphinans, benzomorphans, 4-phenylpiperidines, 4-anilidopiperidines diphenylheptanes, phenylpropylamines, peptides [12]) differing with respect to potency, receptor affinity, subtype selectivity, and other characteristics. A basis for many of these important differences may reside in different ligandreceptor interactions. As the experimental structural information on these interactions is now available only for three $\mu$ OR ligands: the irreversible $\beta$-funaltrexamine $(\beta$ FNA) antagonist belonging to $\mathrm{N}$-substituted $4,5 \alpha$ epoxymorphinans (PDB ID: 4DKL, the inactive $\mu \mathrm{OR}$ crystal structure [9]), the morphinan agonist BU72 (PDB ID: $5 \mathrm{C} 1 \mathrm{M}$, the activated $\mu \mathrm{OR}$ crystal structure [10]), and the peptidic agonist DAMGO [11], identification of 
Scheme 1 Structures of morphine and fentanyl. The $\vartheta_{1}-$ $\vartheta_{4}$ torsion angles are defined by the subsequent three bonds where the middle ones are indicated by the arrows and the terminal are denoted in green

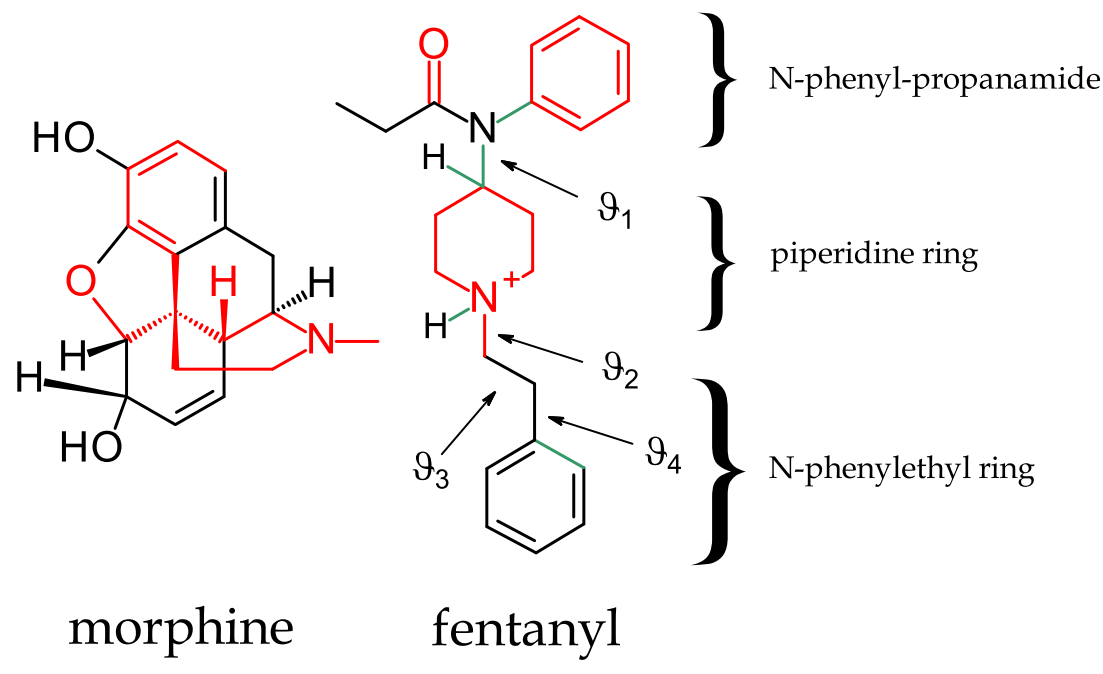

the molecular signatures of binding for molecules coming from other opioid classes is possible only using in silico methods (e.g., [13, 14]). A group of opioids deserving a closer in silico look are 4-anilidopiperidines with molecules of high clinical relevance, such as fentanyl, alfentanil, remifentanil, and sufentanil [15-17].

Comparing fentanyl (N-(1-(2-phenylethyl)-4piperidinyl)-N-phenyl-propanamide, Scheme 1) and the prototypical $\mu \mathrm{OR}$ ligand-morphine, it can be found that both are highly selective $\mu \mathrm{OR}$ agonists, binding to the receptor with similar, nanomolar affinity [18-20]. On the other hand, fentanyl is analgetically much more potent than morphine [5] due to its higher lipophilicity [21]. Regarding the post-binding signaling events, morphine is a more efficient $G$ protein activator. In opposition, fentanyl robustly induces $\mu \mathrm{OR}$ interactions with $\beta$-arrestin [22], receptor phosphorylation [22] and leads to a substantial desensitization and internalization of the receptor [23], while in all these cases morphine is less efficacious. Furthermore, fentanyl-mediated phosphorylation of ERK $1 / 2$ has been shown to be $\beta$-arrestin-dependent, while in the case of morphine it proceeds via a PKC-dependent pathway [24].

Considering the pair in structural terms, both fentanyl and morphine have a protonable tertiary amine in the piperidine ring. On the other hand, fentanyl has only one more structural element able to participate in hydrogen bonding $(\mathrm{C}=\mathrm{O})$, compared to phenolic and hydroxy $-\mathrm{OH}$ and ether - $\mathrm{O}-$ groups of morphine. Fentanyl is also relatively highly flexible, with its seven more or less rotatable bonds (neglecting the $\mathrm{CH}_{3}$ rotations and possibility for the piperidine ring conformation flips), while morphine is essentially rigid [25-28].

How do these structural differences affect the ligand-receptor interactions? Is flexibility, different shape, and rather apolar a structure connected to different molecular signatures of ligand- $\mu \mathrm{OR}$ interactions? As the knowledge on these issues is certainly important from the point of view of the search for novel analgetics, we endeavored to perform a comparative analysis of the behavior of fentanyl and morphine bound to the receptor. To this aim we performed a set of full-atom molecular dynamics (MD)

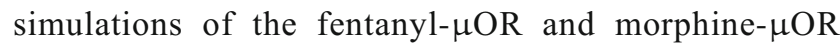
complexes, as well as the simulations of the unliganded receptor (APO). By their means, we attempted to identify molecular signatures (key ligand-receptor interactions, molecular switches) of fentanyl binding and compare them with those of morphine. The obtained characteristics were discussed in the context of experimental findings. To the best of
Table 1 Molecular dynamics variants

\begin{tabular}{llll}
\hline Code & Receptor structure & Sodium at the allosteric site & Ligand \\
\hline APO-IN-NA & $4 \mathrm{DKL}$ & yes & none \\
FENT-IN-NA & $4 \mathrm{DKL}$ & yes & fentanyl \\
MORPH-IN-NA & $4 \mathrm{DKL}$ & yes & morphine \\
APO-ACT & $5 \mathrm{C} 1 \mathrm{M}$ & no & none \\
FENT-ACT & $5 \mathrm{C} 1 \mathrm{M}$ & no & fentanyl \\
MORPH-ACT & $5 \mathrm{C} 1 \mathrm{M}$ & no & morphine \\
\hline
\end{tabular}




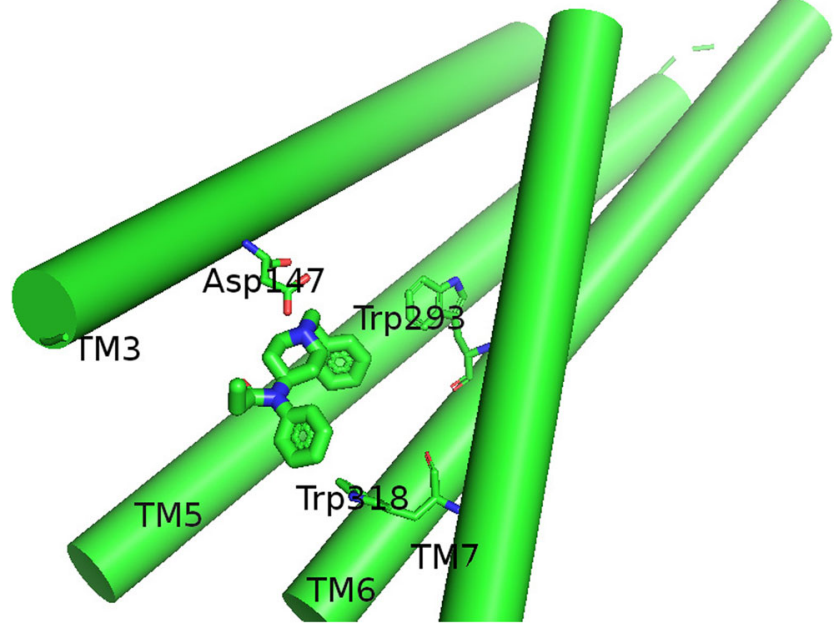

Fig. 1 The initial binding mode of the fentanyl- $\mu$ OR (by manual docking)

our knowledge, it is the first molecular dynamics study on fentanyl bound to the crystal structure $\mu \mathrm{OR}$ by studing the ligand-receptor interactions.

\section{Methods}

\section{The general workflow}

The general workflow of the study was as follows: 1) to identify a ligand binding mode; 2) to perform full-atom molecular dynamics runs with the given binding mode; 3 ) to analyze differences between fentanyl- $\mu \mathrm{OR}$ and morphine- $\mu \mathrm{OR}$ complexes.

\section{Binding mode determination}

For the sake of binding mode determination, we performed manual and automated dockings to both receptor structures: 4DKL (inactive) and 5C1M (active) (with AutoDockVina [29] using default parameters, see below for ligand and receptor preparation details):

(i) With regard to morphine, the manual placement was obtained by superimposing the piperidine ring in morphine and crystallographic ligands. An almost identical binding mode was found as the top scored by automated docking, so it was retained for further study. Both receptor structures yielded the very same binding mode.

(ii) For fentanyl, the automated docking to the inactive receptor without sodium gave poses that were unstable (therefore they are not discussed). If sodium ion was present in the inactive structure, the poses were stable. The manually obtained pose (described below), after some reorganization converged to a stable pose both in fentanyl-4DKL and fentanyl-5C1M complexes, so this one was chosen for extended production run. For further discussion, the binding mode to which several simulations with the inactive and the active structure had converged was chosen (see Table 1).

Regarding the manual docking of fentanyl, it was obtained by superimposing the piperidine ring of fentanyl with that of crystallographic ligands. The N-phenethyl chain was directed toward the intracellular part of the receptor (with an attempt to lay it over the coordinates of N-cyclopropylmethyl of $\beta$ FNA), while 4- $N$-phenylpropanamide toward the receptor
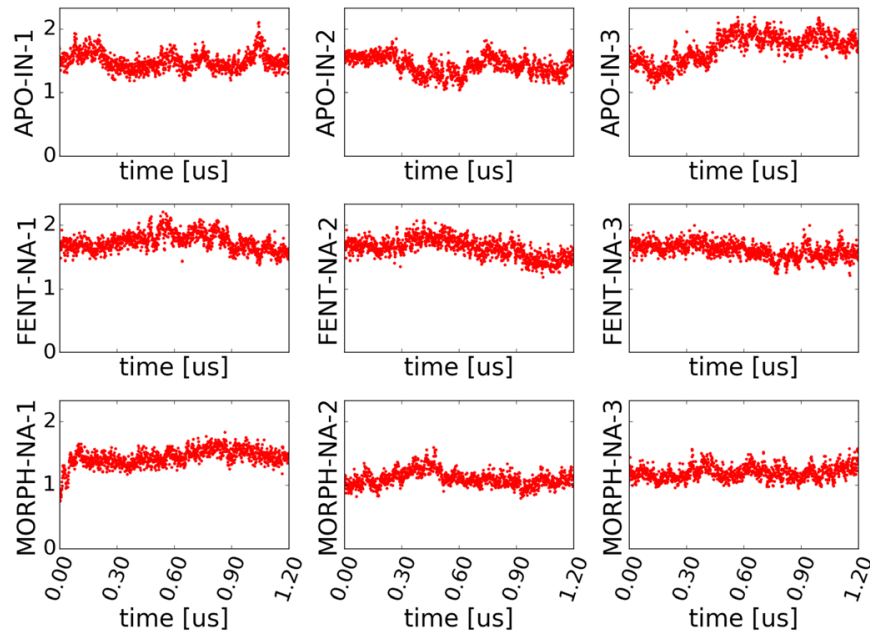

a

Fig. 2 The $\operatorname{RMSD}[\AA]$ as a function of simulation time $[\mu \mathrm{s}]$ in production runs for APO, FENT, and MORPH: (APO-IN-3,2,1; FENT-NA-3, FENT-ACT-1, FENT-ACT-2; and MORPH-ACT-2). The three first
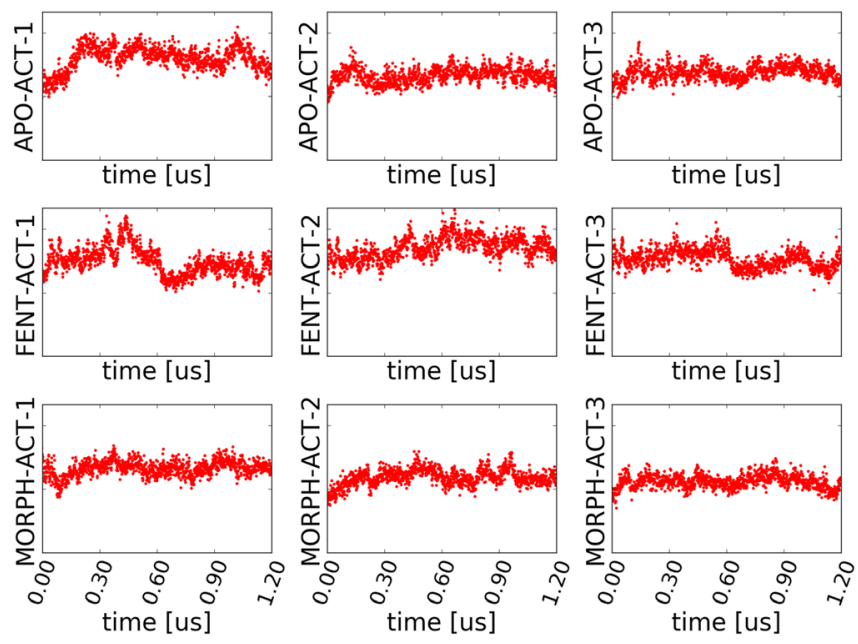

b

columns are for inactive APO, FENT-Na, MORPH-Na (a) and the next three are for active APO, FENT, MORPH (b) 


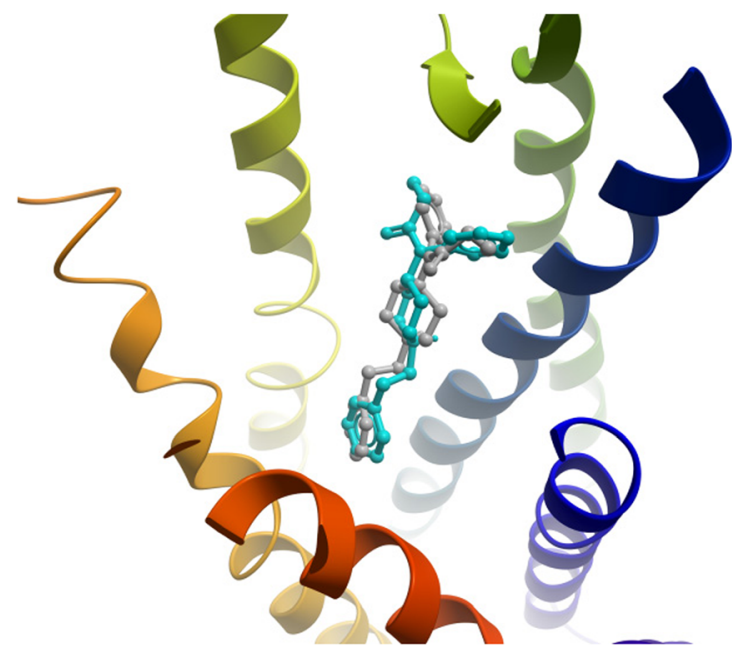

a

Fig. 3 The fentanyl side-chains retain some residual mobility in the binding pocket: a 4- $N$-phenylpropanamide mobility, b N-phenethyl mobility (conformers are represented with different colors). Helices of the receptor are colored from N-terminal (blue) to C-terminal (red)

outlet so that the phenyl pointed to $\operatorname{Tr} 318^{7.35}$. The rationale behind this positioning was that we assumed N-phenethyl of fentanyl is a counterpart of $\mathrm{N}$-phenethyl in $\mathrm{N}$ phenethylmorphine (a $\mu \mathrm{OR}$ agonist) and if $\mathrm{N}$ phenethylmorphine has the alkaloid part oriented similarly to $\beta$-FNA in 4DKL, the N-phenethyl chain must go toward the receptor intracellular part. Further, the activity of a fentanyl derivative substituted at the N-phenethyl chain has been found to be sensitive to mutations of Ser $329^{7.46}$ located around the putative sodium binding pocket toward the intracellular side of the receptor [30]. On the other hand, the activity of a derivative, which is substituted at the para-position of the anilide aromatic ring have been influenced by mutations of Trp318 7.35 and His $319^{7.36}$ [31]. The similar binding mode of fentanyl in the active and inactive receptor structures (see Fig. 1) was found.

The stability of the obtained binding modes (manually or automatically) was checked by several molecular

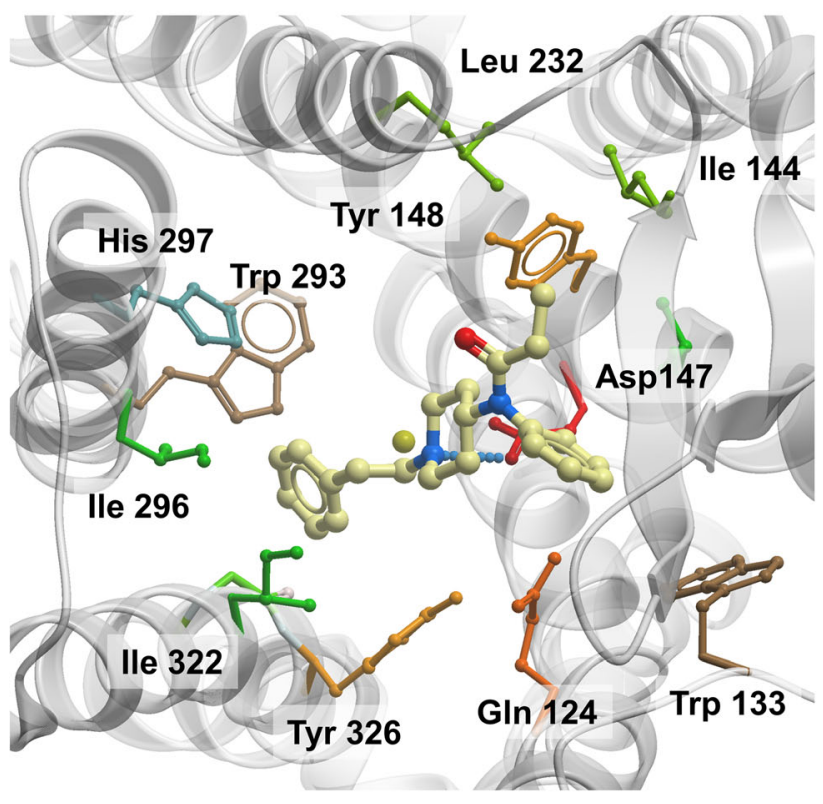

a

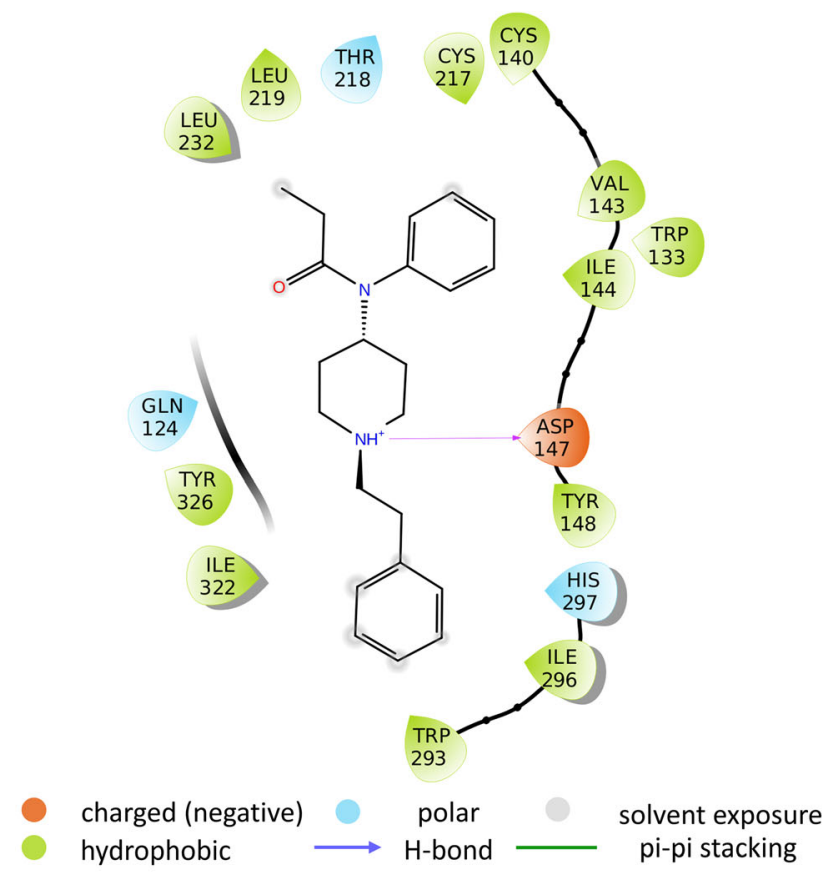

b

Fig. 4 Intermolecular contacts of fentanyl in the receptor cavity presented for FENT-IN-Na ${ }^{+}$a in 3D view and (all helices gray, Leu and Ile green, Asp red, Trp brown, Tyr, Gln orange, His blue) and $\mathbf{b}$ 2D view. Yellow point on left part of ligand is the sodium ion 


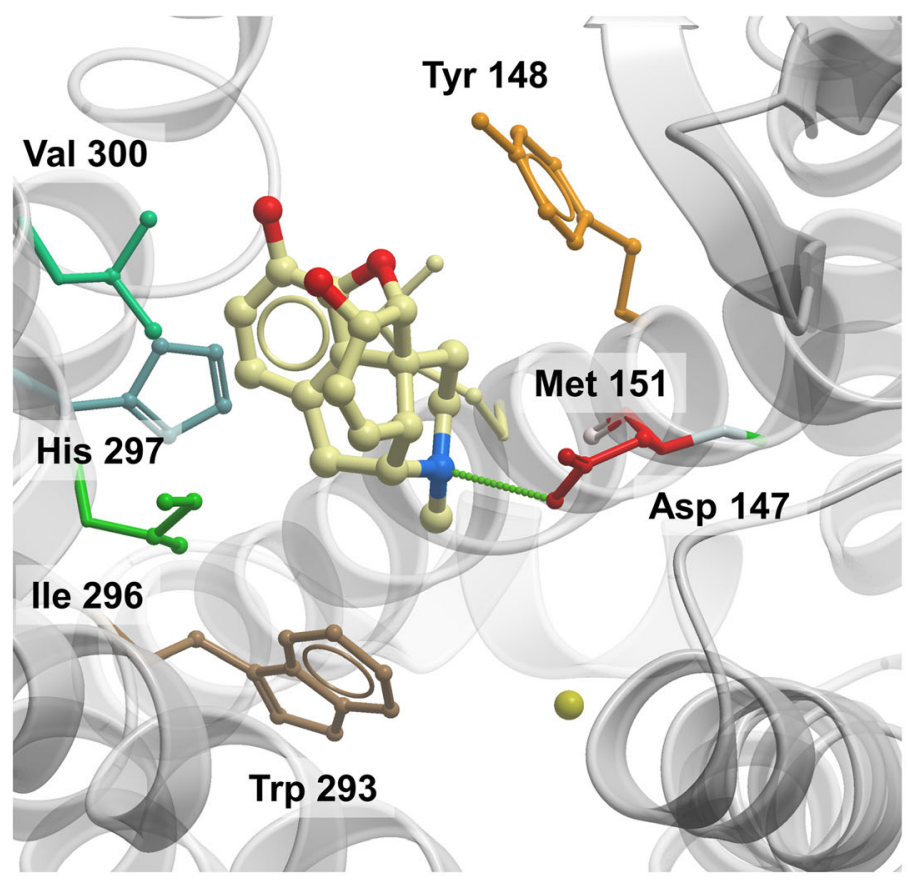

a

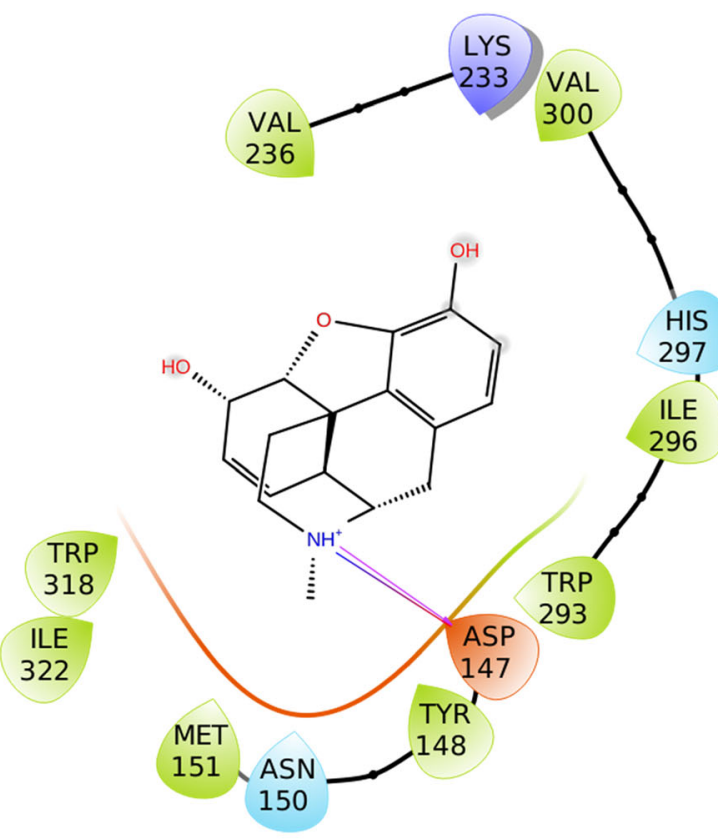

b

Fig. 5 Intermolecular contacts of morphine in the receptor cavity presented for MORPH-IN-Na ${ }^{+}$a in 3D view (all helices gray, Val and Ile green, Asp red, Trp brown, Tyr orange, His blue) and $\mathbf{b} 2 \mathrm{D}$ view. Yellow point on left part is the sodium ion

dynamics runs (of at least 500 ns lengths, for details of MD simulations see below) with the complexes ligand-4DKL and ligand-5C1M. The poses of fentanyl, coming from automatic docking were unstable in simulation. In the case of morphine, the manual/automated docking pose retained a very stable positioning throughout all simulations.

\section{Receptor and ligand preparations}

The 4DKL and 5C1M receptor structures were downloaded from the Orientation of Proteins in Membranes (OPM) database [32]. The OPM structures are pre-oriented protein coordinates with respect to the membrane normal (the $\mathrm{Z}$ axis by definition). The original ligands, the T4 lysozyme fragment in 4DKL, and the nanobody in $5 \mathrm{C} 1 \mathrm{M}$ were removed; as were all other heteroatom (HET) residues found in the structures. Crystallographic water molecules found within the receptor were retained. The missing ICL-3 loop in 4DKL was modeled using the ModLoop server [33]. The disulfide bridge (Cys140-Cys217) was kept as found in the crystallographic structures. A few missing atoms were added automatically in both structures. Unnatural amino acid cysteine-s-acetamide (YCM) found in the position 57 of $5 \mathrm{C} 1 \mathrm{M}$ was manually changed to cysteine.

The piperidine $\mathrm{N}$-atoms of ligands were protonated as expected at physiological $\mathrm{pH}$. The structures were minimized using Gaussian09 [34] at the B3LYP/6-31G(d,p) level. In order to obtain force-field parameters for the ligands, they were submitted to the ParamChem service, which produces parameters compatible with the CHARMM force-field (CHARMM CGenFF) [35].

\section{Molecular dynamics variants}

The molecular dynamics were performed on the system containing: receptor protein, membrane, and solvent. The variants (Table 1) included simulations where the protein structure

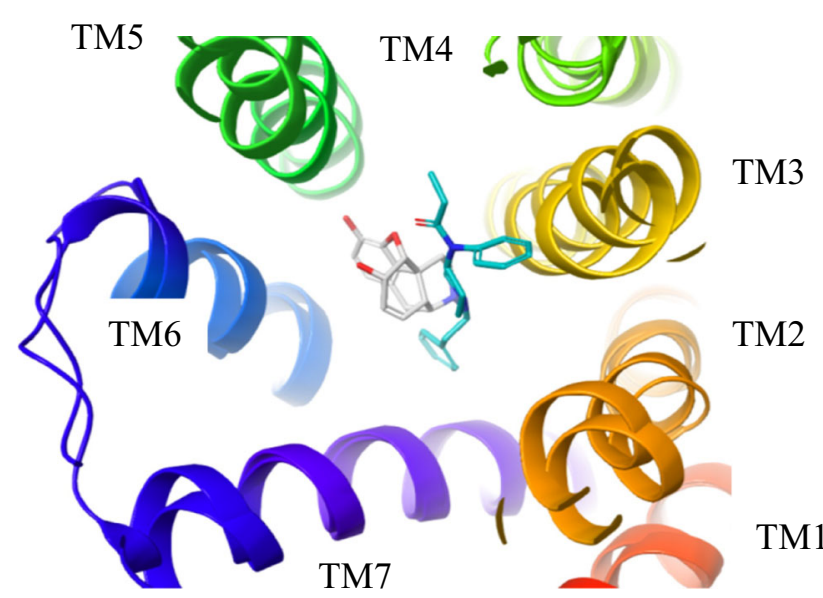

Fig. 6 Overlap of fentanyl and morphine positioning in the $\mu$ OR binding pocket. Helices of the receptor are colored from $\mathrm{N}$-terminal (red) to $\mathrm{C}$ terminal (blue) 

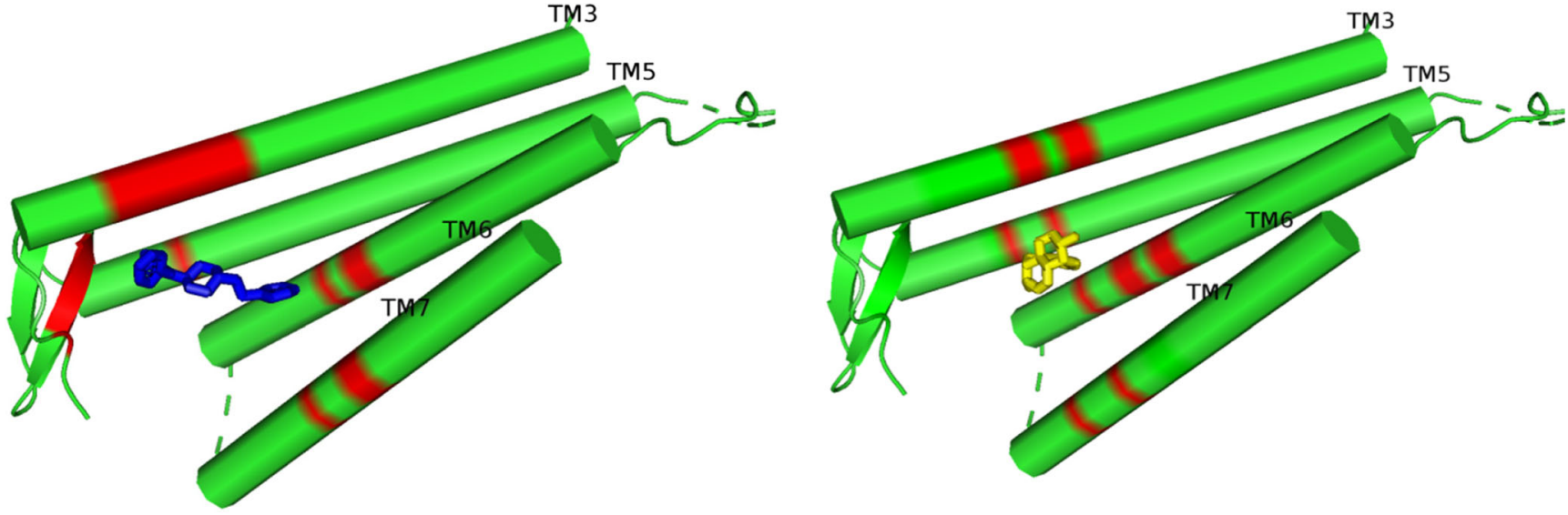

a

b

Fig. 7 Both ligands contact the helices at different residues: a fentanyl (blue) and $\mathbf{b}$ morphine (yellow) in the $\mu \mathrm{OR}$. The residues that are contacted by the ligand are marked in red (simplified depiction)

came from either the inactive crystal 4DKL (denoted with -IN postfix) or the active crystal 5C1M (denoted with ACT).

The binding pocket was occupied by either fentanyl (denoted with FENT- prefix) or morphine (denoted with MORPH- prefix). Alternatively, simulations without a ligand were also performed (denoted with APO- prefix). In the case of the 4DKL complexes, we prepared systems with (-IN-NA) or without a sodium cation (simply -IN postfix) placed at the allosteric site (close to Asp $114^{2.50}$ ), but as most of simulations without allosteric sodium gave unstable fentanyl behavior, this variant is not discussed in the text. In the case of the empty 4DKL receptor, sodium entered the allosteric site within several nanoseconds from the simulation start, so we treat these runs in aggregate with other-IN-NA simulations.

\section{Molecular dynamics protocol}

The MD simulation systems were prepared with the help of CHARMM-GUI service [36]. The receptor was inserted into the POPC membrane (145 lipid molecules, the replacement method was used), and the system was solvated with water (about 13,000 water molecules, the TIP3P water mode was used). $\mathrm{Na}^{+}$and $\mathrm{Cl}^{-}$ions were added so as to obtain $0.154 \mathrm{M}$ concentration. The size of the final systems (rectangular box) was $78.88 \times$ $78.88 \times 111.18 \AA$. The CHARMM36 force-field was used [36] or the protein, lipids, water, and ions. Energy minimization and MD simulations were performed using GROMACS 5.1.2. [37]. After the minimization, the

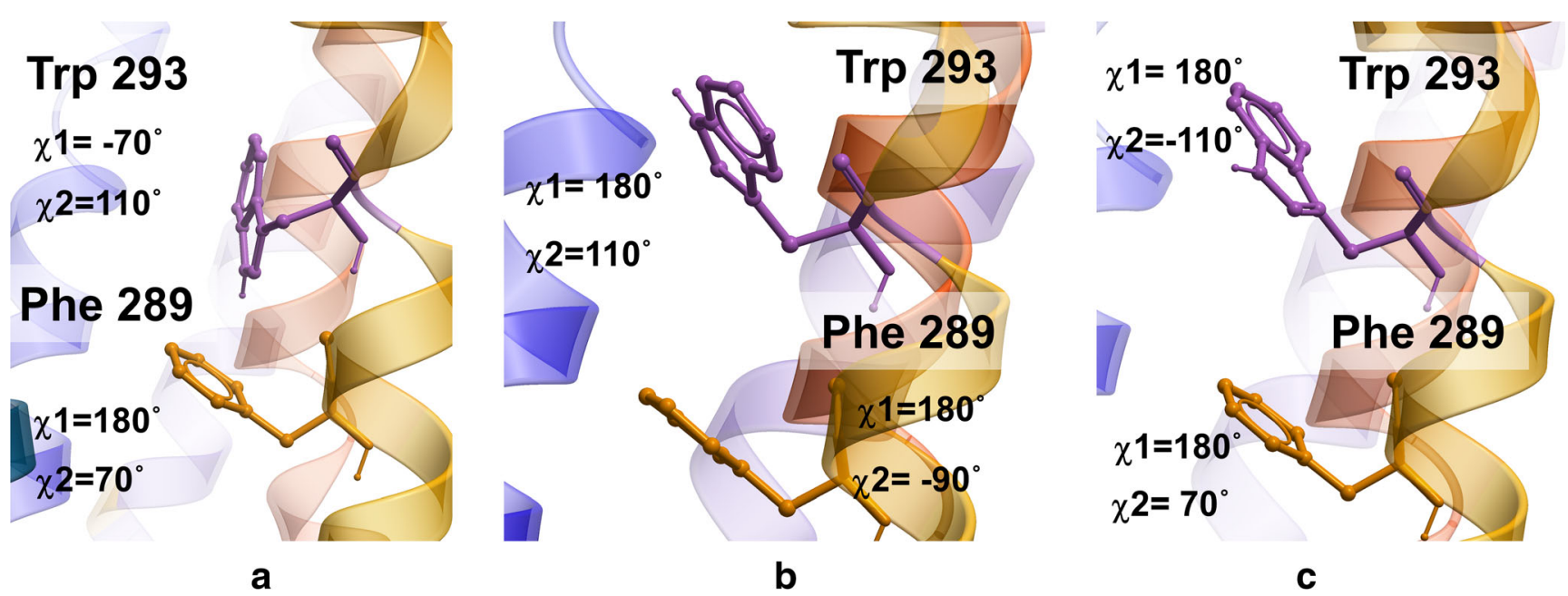

Fig. 8 The Trp293 $3^{6.48}$ rotameric states found in the simulations: a MORPH and the majority of APO simulations; $\mathbf{b}$ and $\mathbf{c}$ FENT simulations. Note that rotameric states of Phe $289^{6.44}$ are very similar in all cases 
system was subject to six steps of equilibration [38] (as defaulted in the CHARMM-GUI service). The NVT dynamics (constant volume and temperature) was used for the first and second step, and the NPAT (constant pressure, area, and temperature) dynamics for the other steps at $303.15 \mathrm{~K}$. The parameters used in the production step were as follows: NPAT ensemble, $303.15 \mathrm{~K}$, integration step $=2$ fs, cut-off scheme Verlet, Nose-Hoover thermostat, Parrinello-Rahman barostat, LINCS H-bonds constraints. MD results were analyzed using GROMACS, VMD, and in-house Python scripts (using the MDAnalysis library [39]).

The proper production runs were extended to obtain at least $1.2 \mu$ s simulation time after the stabilization of the binding mode. The production simulations were done in three replications. The protein RMSD for the APO, FENT and MORPH simulations (Fig. 2) fluctuates around similar values. Thus, the ligands undergo comparably small conformational changes as indicated by their RMSD values. This suggests higher stability of the ligand-receptor system in the case of morphine is present in the binding pocket than when it is either empty or is occupied by fentanyl.

\section{Results and discussion}

This chapter contains the description of our MD simulation results: (i) the fentanyl and morphine binding modes supplemented by mutagenesis data, (ii) the description of the differences in the dynamic behavior of the binding site residues, and (iii) the principle components analysis. The discussion of presented results finishes this chapter.

\section{Fentanyl binding mode}

We undertook several approaches for the determination of the fentanyl binding mode. Our idea was to find the binding mode by bridging molecular docking and molecular dynamics (following the workflow similar to the one proposed in ref. 40). The ligand was docked either manually or automatically to the binding site of: i) the inactive receptor without a sodium cation present in the allosteric site (4DKL, FENT-IN), ii) the inactive receptor with a sodium cation present in the allosteric site (4DKL with sodium at Asp114 $4^{2.50}$, FENT-IN-NA), and iii) the active receptor (FENT-ACT), see "Binding mode determination".

Molecular dynamics runs of length up to at least $500 \mathrm{~ns}$ were performed in all cases. The simulations with unstable behavior of fentanyl in the binding site were discarded. For example, no stable fentanyl positioning was found in FENTIN simulations, and therefore this configuration was omitted from further investigations. Finally, a single binding mode to which several FENT-IN-NA simulations and FENT-ACT simulations had converged was chosen for the extended MD runs. Therefore, similar interactions in the binding pocket for both FENT-IN-NA (Fig. 4) and FENT-ACT (Fig. SM-1) were observed.

In this binding mode, the protonated amine of the piperidine ring interacts stably with Asp $147^{3.32}$, as expected of high-affinity $\mu \mathrm{OR}$ agonists. The $\mathrm{N}$-phenethyl chain is oriented toward the intracellular side, while the 4-Nphenylpropanamide chain toward the extracellular side. Both these chains retain some residual mobility and in some simulations a sort of rotational alternation can be observed without the overall change of the binding mode (Fig. 3a and b).

Figure 4 presents the intermolecular contacts of the fentanyl- $\mu$ OR complex (3D and 2D projections). Apart from the mentioned charge-assisted hydrogen bonding pipNH ${ }^{+} \ldots$ Asp $147^{3.32}$, the piperidine ring also forms hydrophobic interactions with Gln $124^{2.60}$ and for some time with Ile $322^{7.39}$ or Tyr $326^{7.43}$. The N-phenethyl chain in the most frequent arrangement is localized so that the aromatic ring of fentanyl forms hydrophobic contacts with Tyr $326^{7.43}$ for some of the simulation periods with Ile296 $6^{6.51}$ and Ile $322^{7.39}$ (dependent on the rotamer of the N-phenethyl chain) and/or with Trp293 ${ }^{6.48}$ (dependent on the rotameric state of the $\operatorname{Trp} 293^{6.48}$ side chain). As to the $4-\mathrm{N}$-phenylpropanamide terminus, two groups of residues interact either with the phenyl ring or with the propionyl chain of fentanyl. The first grouping involves: Gln $124^{2.60}, \operatorname{Trp} 133^{\mathrm{ECL} 1}, \mathrm{Val143} 3^{3.28}$, Cys $217^{\mathrm{ECL} 2}$, Asp216 $6^{\mathrm{ECL} 2}$ and the second one: Ile144 ${ }^{3.27}$, Tyr148 ${ }^{3.33}$, Thr218 ${ }^{\text {ECL2 }}$, Leu219 $9^{\text {ECL2 }}$, Leu232 $2^{5.38}$.

Additionally, we observed that the 4-Nphenylpropanamide may interact with His54 of the receptor $\mathrm{N}$-terminus in the active structure (FENT-ACT) where the flexible $\mathrm{N}$-terminus of the receptor is present. One can take into account that experimentally, there is some evidence that $\mathrm{N}$-terminus is important for fentanyl's binding (lowering the $\mathrm{K}_{\mathrm{D}}$ by ten times upon $\mathrm{N}$-term deletion) but not for that of morphine [41].

\section{Morphine binding mode}

In the case of morphine, the determination of the binding mode was straightforward, after only a very minor readjustment from the pose obtained by manual docking. In both the active and the inactive receptor (MOR-IN-NA, MOR-ACT), morphine keeps a very stable positioning throughout all simulations, and therefore similar interactions in the binding pocket for both MORPH-IN-NA (Fig. 5) and MORPH-ACT (Fig. SM-2) were observed.

The intermolecular contacts (see Fig. 5) between the ligand and $\mu \mathrm{OR}$ involves first and foremost the interaction of the protonated amine with Asp $147^{3.32}$. The oxygens of the phenol, hydroxy, and ether groups are oriented toward the extracellular side and exposed to interactions with the solvent 

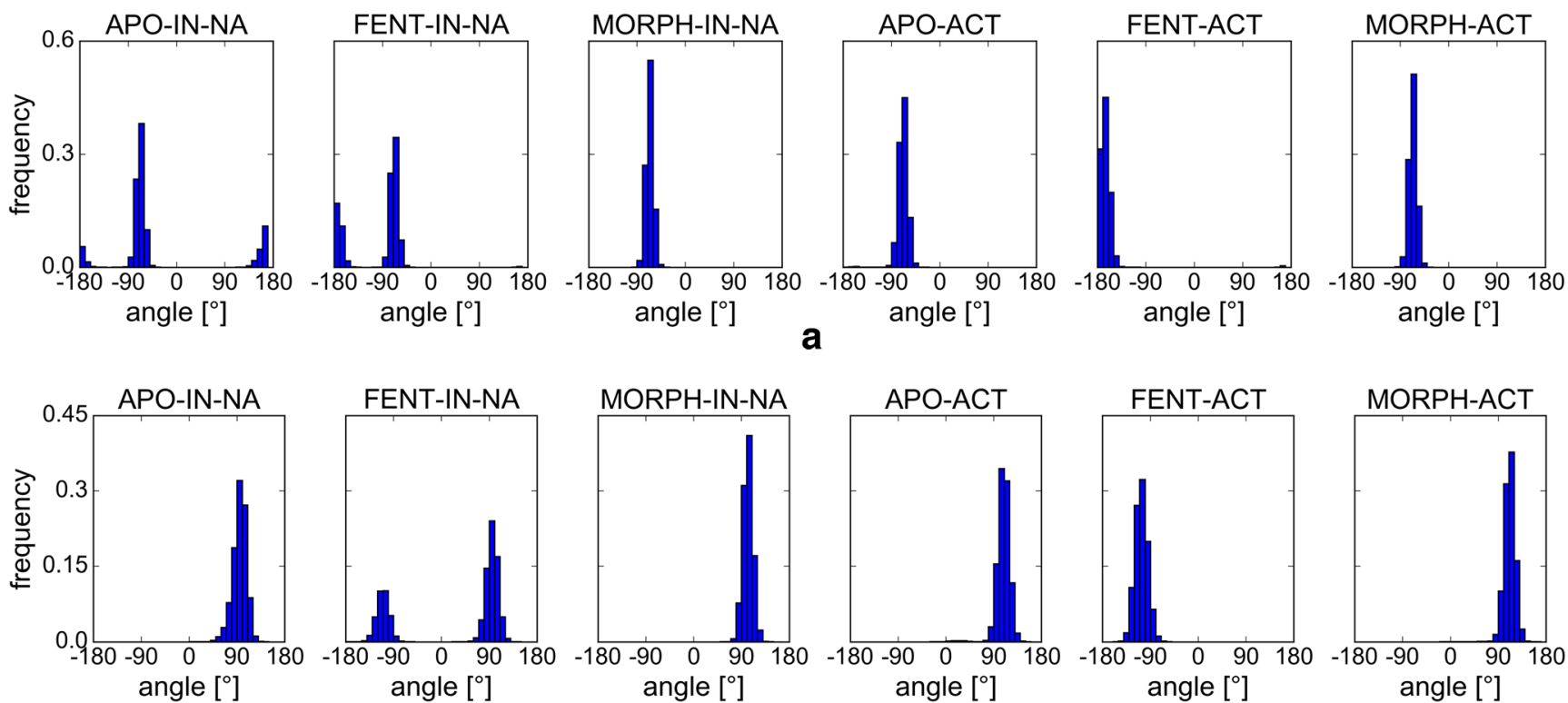

b
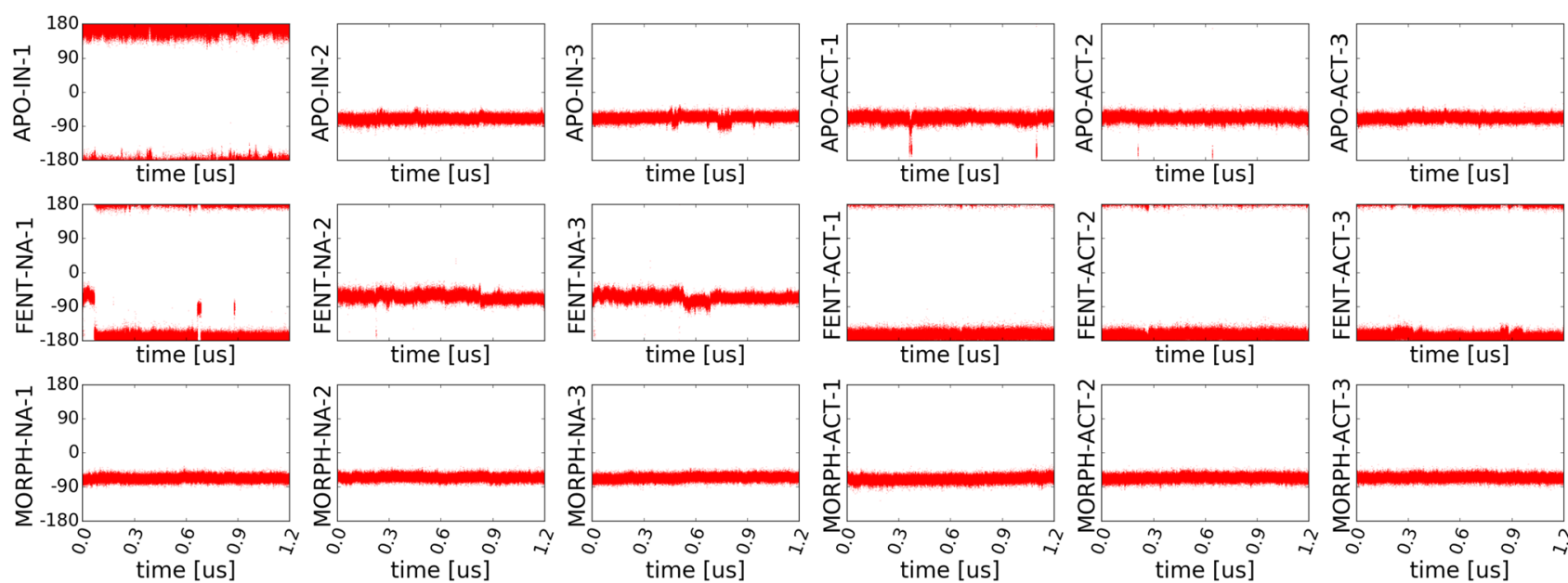

time [us]

time [us]

C
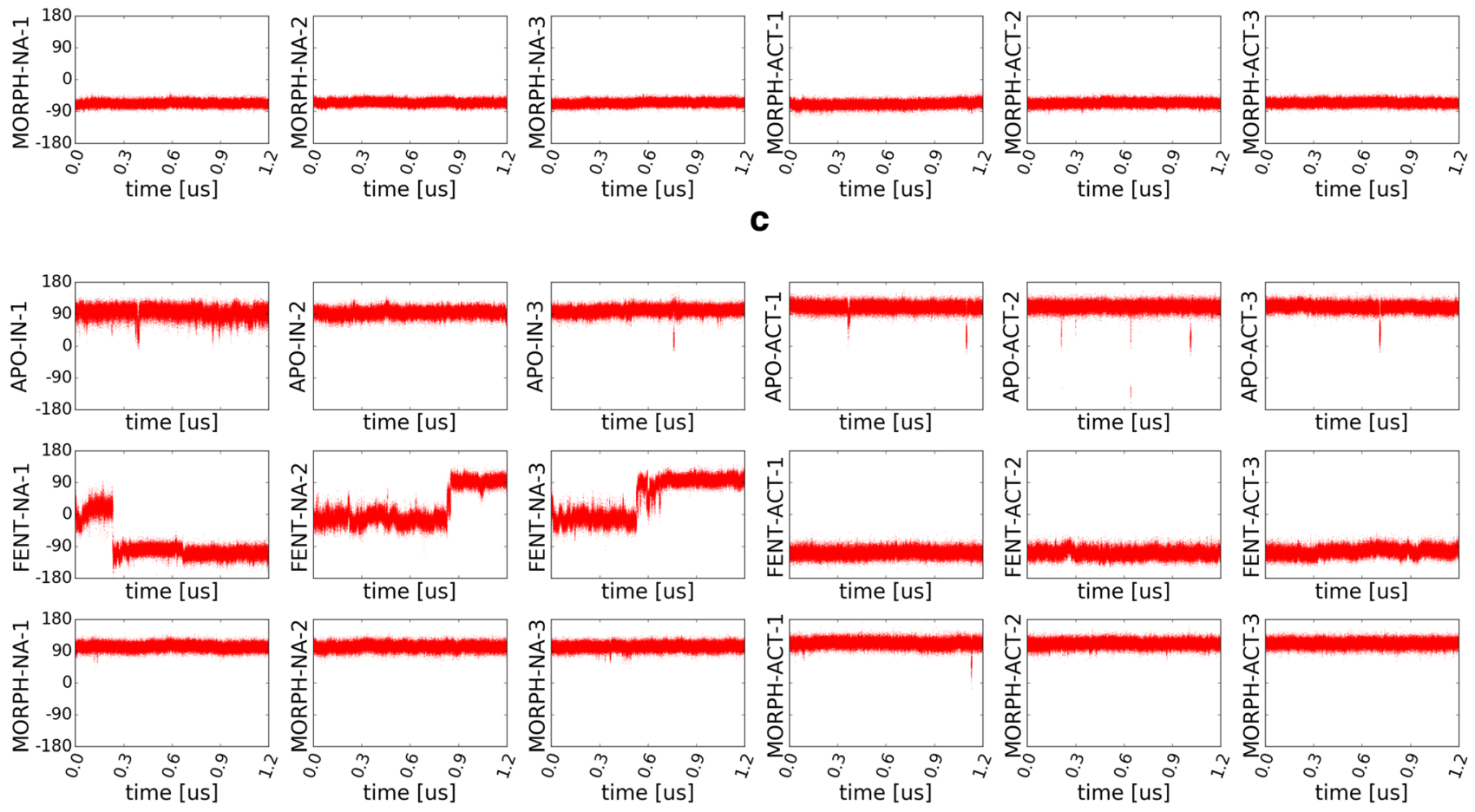

time [us]

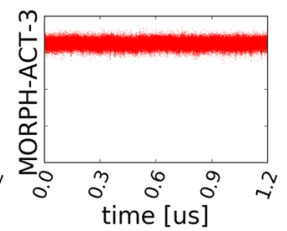

d 
Fig. 9 Distributions of $\operatorname{Trp} 293^{6.48}$ dihedral angles: a $\chi_{1}, \mathbf{b} \chi_{2}$. The histograms are made based on the last $300 \mathrm{~ns}$ for three replications (900 ns in total); The plots $\mathbf{c}$ and $\mathbf{d}$ show time dependences of $\chi_{1}$ and $\chi_{2}$ for Trp $293^{6.48}$ during $1.2 \mu$ s simulations. Each component picture demonstrates a separate simulation. The top, middle, and bottom row correspond to APO, FENT, and MORPH, respectively. Observe that only for FENT are different values of the torsion angles stabilized

molecules hydrating the binding site. The water molecules in the direct vicinity of these oxygens form a water network contacting for example Tyr148 $8^{3.33}$. Morphine is also involved in a number of stable hydrophobic interactions with Met151 $1^{3.36}$, Val236 $6^{5.42}$, Trp293 ${ }^{6.48}$, His $297^{6.52}$, Ile296 $6^{6.51}$, Val300 $6.55, \operatorname{Trp} 318^{7.35}$, Ile $322^{7.39}$, Asn $150^{3.35}$, and Lys $233^{5.39}$. Such a binding mode is generally similar to the ones found in crystallography for a 4,5- $\alpha$-epoxy-morphinan antagonist $\beta$-funaltrexamine [9] or for a more distant agonist derivative BU72 [10]. It is also consistent with other modeling studies that dealt with morphine so far $[42,43]$.

\section{The data emerging from the $\mu O R$ mutagenesis}

The description of the binding modes of both ligands is supported by mutagenesis data:

(i) First and foremost, both studied ligands exhibit an ionic interaction with Asp $147^{3.32}$. The mutation of this residue for alanine or asparagine (able to form H-bonds but not ionic interactions) lowers the $\mu \mathrm{OR}$ affinity of morphine more than 30 times [44]. Such a drastic drop is not observed with the Asp147Glu mutation [44], where the side-chain is negatively charged (as in Asp), but longer by one $-\mathrm{CH}_{2}-$ unit which is apparently suboptimal, still demonstrating, however, the necessity of the $\mathrm{N}^{+} \mathrm{H}$... $\mathrm{COO}^{-}$interaction in $\mu \mathrm{OR}$ binding. No data on the Asp14 $7^{3.32}$ mutations are available for fentanyl; however, it is reasonable to suppose that the importance of the interaction also holds true for 4-anilidopiperidines (as a general rule in aminergic GPCRs). "Carba"-derivative of fentanyl was reported to bind with much weaker affinity [45].

(ii) Both ligands interact either directly (H-bonds) or indirectly (H-bonds through a bridging water molecule) with Tyr148 3.33 . This corresponds to the effect of Tyr148Phe mutation [44], upon which such an interaction is not possible (there are no atoms in the side-chain able to form an $\mathrm{H}$-bond), and which was reported to bring about a threefold drop in morphine affinity and a 2- to 7-fold drop in affinity of ohmefentanyl stereoisomers.

(iii) An identical mutation on Tyr326 $6^{7.43}$, namely Tyr326Phe, was reported to cause a significant deterioration in fentanyl affinity (more than 72 times), while a not so dramatic one for morphine (about six times) [46]. In our simulations, for neither of the ligands there exists a direct H-bonding interaction with Tyr326 ${ }^{7.43}$. On the other hand, Tyr326 $6^{7.43}$ is involved in the interaction with Asp147.32 (previously called "the 3-7 lock"). The interaction is either direct or mediated by a water molecule (or dissolved). Our simulations show (these results are described in "Differences in the dynamic behavior of the binding site residues") that this contact is tighter for fentanyl. Hypothetically, the presence of the H-bonding ability in this residue is important for adequate positioning of the side chains for $\mu \mathrm{OR}$ interactions with fentanyl, and therefore a mutation depriving such a function impacts fentanyls' affinity to a much greater extent than that of morphine.

(iv) A mutation where the effect on affinity and potency is clear for morphine ( $5 \mathrm{x} \downarrow$ affinity) but not for fentanyl (2 $\mathrm{x} \downarrow$ affinity) is Trp318Leu [47]. In our simulations, fentanyl did not form stable contacts with $\operatorname{Trp} 318^{7.35}$. Contrarily, morphine did form hydrophobic interactions, so an exchange for a smaller side-chain resulting in a smaller contact surface should consequently bring about some lowering of the affinity.

\section{A generalized glance at both ligands}

In a generalized view (Fig. 6), both morphine and fentanyl interact with TM3, TM5, TM6, and TM7. The positioning of fentanyl and morphine overlap only to a minor extent (Fig. 7), even though some of the contacts are present in both cases (Figs. 4 and 5). Notably however, the extent of these contacts does differ in both cases.

Fentanyl's atoms are in the proximity (closer than 7.0 ̊) of as many as seven TM3 residues, while for morphine it is only four residues. The situation is somehow reverse if TM6 is considered. Here, morphine is able to contact five TM6 residues, and fentanyl only three. Regarding TM7, both ligands are in contact to a similar extent, but its place is different. Morphine interacts closer to the extracellular side $\left(\operatorname{Trp} 318^{7.35}\right)$, and fentanyl at the bottom of the binding pocket (Tyr326 ${ }^{7.43}$ ). Fentanyl, as it stretches toward the extracellular side with the 4- $\mathrm{N}$-phenylpropanamide chain, is also able to reach ECL1, ECL2, and the N-terminus (present in $5 \mathrm{C} 1 \mathrm{M}$ structure).

\section{Differences in the dynamic behavior of the binding site residues}

The comparison of the experimental structures in the inactive and active crystal forms has revealed main "micro-switches" to explain the inhibition/activation mechanism of GPCR. There are putative "Trp rotamer toggle switch" and breaking/creating of "3-7 lock" [48, 49]. Apart from contacting different residues of the $\mu \mathrm{OR}$ binding pocket than 
morphine, fentanyl contacts the elements common to both ligands but induces some different effects. These include the conformation of: Trp293 $3^{6.48}$, Asp $147^{3.32}$, and Tyr320 $0^{7.43}$.

The first of the mentioned residues, highly conserved amino-acid Trp $293^{6.48}$, seems particularly important since it has been thought to be directly involved in the activation process in the so-called "Trp rotamer toggle switch" (called "transmission switch" too [49]). This "micro-switch" hypothesis was based on the MC simulation of the TM6 in cannabinoid $\mathrm{CB}_{1}$ receptor $[50,51]$. More recent MD simulations performed on inactive and activated $\mu \mathrm{OR}$ crystal structures seem to support it [52-54]. This residue links the agonist binding site with the movement of TM5 and TM6 through the rearrangement of the TM3-5-6 plane. In our simulations, the differences in $\chi_{1}$ and $\chi_{2}$ angles in Trp293 $23^{6.48}$ are clearly seen for morphine and fentanyl interactions with $\mu \mathrm{OR}$. Therefore, we monitor the process through the Trp $293^{6.48}$ movement, which can be evidenced by the time course of the $\chi_{1}$ and $\chi_{2}$ angles.

In the inactive $4 \mathrm{DKL}$ crystal structure of receptor, Trp293 $3^{6.48}$ has dihedral angles $\chi_{1}=-77^{\circ}$ and $\chi_{2}=79^{\circ}$, while in the active crystal structure $5 \mathrm{C} 1 \mathrm{M}$, these values read $-87^{\circ}$ and $121^{\circ}$, respectively. The simulations of the empty receptor started from either the active ( 3 out of 3 APO-ACT replications) or the inactive ( 2 out of 3 APO-IN-NA replications) converge to values of about $-70^{\circ}$ and $110^{\circ}$, respectively (Fig. $8 \mathrm{a}$ and b). However, one APO-IN-NA simulation results in another rotamer of $\operatorname{Trp} 293^{6.48}\left(\chi_{1} \sim 180^{\circ}\right.$ and $\chi_{2} \sim 110^{\circ}$, presented in Fig. 8b). The first option is unexceptionally present in MORPH-IN-NA and MORPH-ACT simulations. In the case of FENT, both possibilities are sampled and additionally, a third rotamer appears $\left(\chi_{1} \sim 180^{\circ}\right.$ and $\chi_{2} \sim-110^{\circ}$, see Fig. $8 \mathrm{c})$. The $-70^{\circ} / 110^{\circ}$ rotamer is associated with a particular, stabilized conformation of the N-phenethyl chain $\left[\mathrm{t}, \mathrm{g}^{-}, \mathrm{g}^{-}\right]$, and with the chain flexibility at $\vartheta_{2}$ and $\vartheta_{4}\left(\left[\mathrm{t} / \mathrm{g}^{-} / \mathrm{g}^{+} ; \mathrm{t}, \mathrm{g}^{-} / \mathrm{g}^{+}\right]\right.$ conformers (for $\vartheta$ definitions see Scheme 1).

To better understand the structural changes for Trp293 $3^{6.48}$, the distributions of two dihedral angles are presented in Fig. 9a, b, and the time evolution of these angles is illustrated in Fig. 9c, d.

The positions of the $\chi_{1}$ and $\chi_{2}$ torsional angles in the APO, MORPH, and FENT simulations can be easily read from the angle distributions (Fig. 9a and b). Observe that in the APO and FENT simulations based on the inactive receptor, two positions of the $\chi_{1}$ angle are found, while in the other simulations only one value is populated (Fig. 9a). It seems to be important that MORPH simulations indicate the same value of $\chi_{1}$ for both inactive and active receptor structures. Moreover, the $\chi_{1}$ angle in APO simulations of the active receptor structure is practically the same. In contrast, in FENT simulations based on the active structure of receptor the $\chi_{1}$ angle is very clearly different and equal to ca. $-160^{\circ}$ (Fig. 9a). On the other hand, the $\chi_{2}$ torsional angle value is split only for the FENT simulations based on the inactive receptor (Fig. 9b).
Interestingly, the $\chi_{2}$ values in APO and MORPH simulations are basically identical in the inactive or active receptor. Again, the value of the $\chi_{2}$ angle is very clearly different than that in APO and MORPH simulations, and it equals ca. $-110^{\circ}$ (Fig. 9a). The exceptional values of the $\chi_{1}$ and $\chi_{2}$ torsional angles in the FENT simulations evidently distinguish the fentanyl interactions with $\mu \mathrm{OR}$ from those of morphine.

The time dependences of the $\chi_{1}$ and $\chi_{2}$ torsional angles in the APO, MORPH, and FENT simulations (Fig. 9c and d) confirm the image given by the angle distributions (Fig. 9a and $b$ ). Indeed, there are two $\chi_{1}$ angle values for the APO and FENT simulations based on the inactive receptor and one for all the other simulations (Fig. 9c). As before, the $\chi_{1}$ angle indicated by the time dependence in the FENT simulations of the active receptor structure is different than that in the APO and MORPH ones. Similar conclusions can be drawn based on the time dependences of the $\chi_{2}$ torsional angle (Fig. 9d).

Additionally, we determined the number of water molecules within $5 \AA$ from Asp114 2.50 , as the hydration of Asp $114^{2.50}$ is connected with the rotation of Trp293 ${ }^{6.48}$, which opens the space toward the cell interior for water influx. The distribution of the number of water molecules is presented in Fig. 10. It appeared that the number of water molecules in all APO, FENT, and MORPH simulations in the inactive receptor structure is similar (from 4 to 11 , within the statistical fluctuations) and does not differentiate the ligands. Also, the number of water molecules and distribution shape in the APO, FENT, and MORPH simulations in the active receptor structure are practically identical (from 4 to 9 ) and do not differentiate fentanyl from morphine.

The $\chi_{1}$ and $\chi_{2}$ dihedral angles in Phe2896.44 and Trp293 $3^{6.48}$ are known to be correlated [44]. The time dependence of the torsional angles in Phe289 $9^{6.44}$ is presented in Fig. 11a. Two positions of the $\chi_{1}\left(\right.$ ca. $\left.-180^{\circ}-100^{\circ}\right)$ are observed in the inactive receptor. However, for APO and MORPH the $\chi_{1}$ equal to ca. $-100^{\circ}$ occurs rather occasionally, whereas for FENT $\chi_{1}=-100^{\circ}$ is stable for quite a significant part of the simulations (Fig. 11a). On the other hand, in the active receptor for both: APO, MORPH, and FENT simulations only $\chi_{1}=$ $-180^{\circ}$ is present (Fig. 11a). In the inactive receptor, two positions of the $\chi_{2}\left(\mathrm{ca} .-100^{\circ}\right.$ and $\left.90^{\circ}\right)$ are observed for APO and MORPH simulations but for FENT ones, in the earlier stage of simulations, up to $0.9 \mu \mathrm{s}$, from 2 to 5 values of $\chi_{2}$ can be observed, but eventually the same two angles seem to be populated ca. $-100^{\circ}$ and $90^{\circ}$ (Fig. $11 \mathrm{~b}$ ). In the active receptor, the same two positions of the $\chi_{2}\left(\mathrm{ca} .-100^{\circ}\right.$ and $90^{\circ}$ ) are observed for all simulations, but for APO and MORPH, flips between the two angles are very frequent, while for FENT the flips are occasional. The frequency of changes of the $\chi_{1}$ and $\chi_{2}$ dihedral angles in Phe289 $9^{6.44}$ in FENT with respect to APO and MORPH seem to be the main difference of interaction between fentanyl and morphine with $\mu \mathrm{OR}$. 

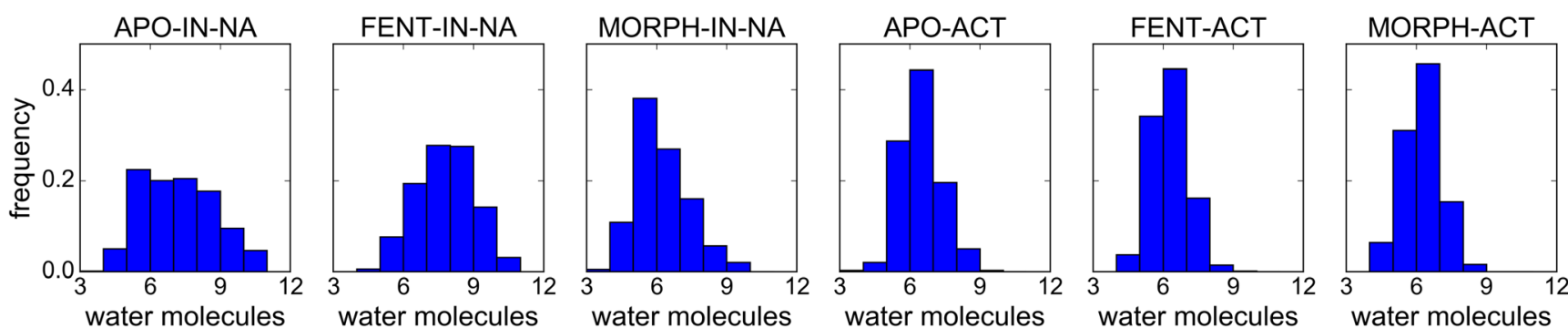

Fig. 10 The distribution of the number of water molecules within $5 \AA$ from any atom of Asp $114^{2.50}$. The histograms are made based on data from the last $300 \mathrm{~ns}$ of three replications (in total $900 \mathrm{~ns}$ )

We also observe changes of the hydrogen bond between Asp $147^{3.32}$ and Tyr $320^{7.43}$. It has been speculated to be involved in "the 3-7 lock", i.e., the breaking of the link between TM3 and TM7 during the activation, which is realized by the breaking of a hydrogen bond between Asp $147^{3.32}$ and
Tyr $320^{7.43}$. It has been suggested to play a key role in the activation of the $\mu \mathrm{OR}$. Opening of "the 3-7 lock" was the first switch proposed to activate the rhodopsin. Here, the lock behavior is demonstrated in the form of distributions (Fig.12a) and time evolutions of the distance between
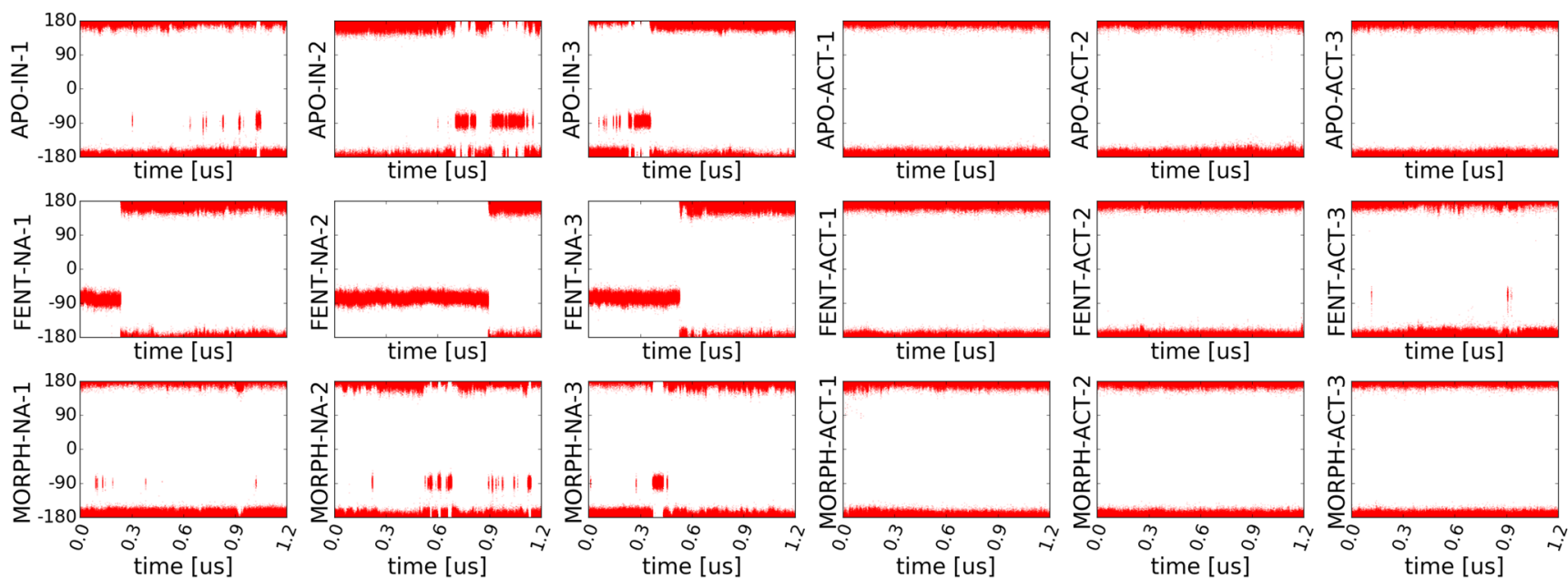

a
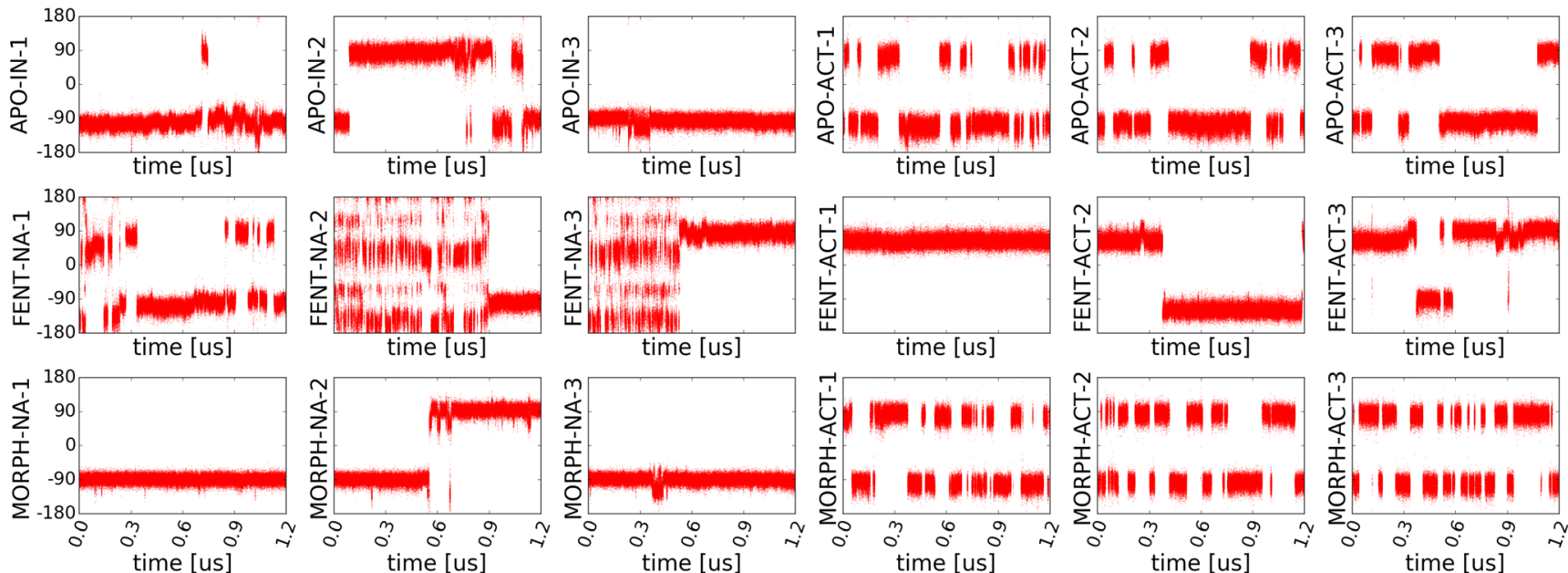

b

Fig. 11 The Phe $289^{6.44}$ a $\chi_{1}$ and $\mathbf{b} \chi_{2}$ dihedral angles time dependences of the $\chi_{1}$ and $\chi_{2}$ during $1.2 \mu$ simulations. Each component picture demonstrates a separate simulation. The top, middle, and bottom rows correspond to APO, FENT, and MORPH, respectively 
Asp $147^{3.32}$ and the Tyr326 7.43 (Fig. 12b). When fentanyl is in the binding pocket, the Tyr326 $6^{7.43}$ hydroxyl group remains closer to Asp147.32 than when morphine is bound. It is particularly visible in FENT-IN-NA simulations, where distribution of the $\operatorname{Tyr} 326^{7.43} \mathrm{O}(\mathrm{H}) \ldots \mathrm{CG}$ Asp $147^{3.32}$ distance is focused around $5.0 \AA$, while for MORPH-IN-NA there is a shift toward higher values and for APO-IN-NA it is usually distributed around $7.0 \AA$ (Fig. 12). The time evolutions support the image yielded by distributions (Fig. 12b).

Additionally, except for the distribution of the Tyr $326^{7.43}$ O...CG Asp $147^{3.32}$ distance, the observation of the Asp $147^{3.32} \chi_{1}$ dihedral angle changes are very important. These parameters, the distribution of the distance and the time during simulations, are presented in Fig. 13a, b.

In this case, the distributions for the inactive receptor almost do not change in the active one (Fig. 13a) for the two ligands, morphine and fentanyl. Notice, however, that only one angle is populated for MORPH, while there are two for FENT and APO simulations. The time evolution supports the image yielded by distributions (Fig. 13b). dependence of Asp $147^{3.32} \chi_{1}$ dihedral angle for Asp147 $7^{3.32}$

\section{Principal component analysis}

The structural variability observed in the simulations was also investigated by the means of principal component analysis [55]. For the sake of analysis, only the last $300 \mathrm{~ns}$ of the simulations were taken into account. The data from different runs were pooled so to obtain a common subspace.

The first principal component (PC1) accounts for as much as $46 \%$ of the observed variance. The further four PCs are associated with 6\% (PC2 and $\mathrm{PC} 3$ ), 4\% (PC4), and 3\% (PC5) variability. The plot of $\mathrm{PC} 2$ vs $\mathrm{PC} 1$ reveals clear clustering (Figs. 14 and 15). The points corresponding to the INNA runs gather at the low extremum of $\mathrm{PC} 1$, while those of the ACT runs at the high extremum thereof. Thus, it seems that the movement associated with PC1 corresponds to the large helical movements on the activation pathway. Indeed, it is what is revealed by the visual inspection of the trajectory projections on the average structure from PCA along the PC1 (Fig. 16).

Notably, there is also some less pronounced grouping within the 'active'/'inactive' clusters. The APO-IN-NA generally has the lowest values. FENT-IN-NA groups in the middle
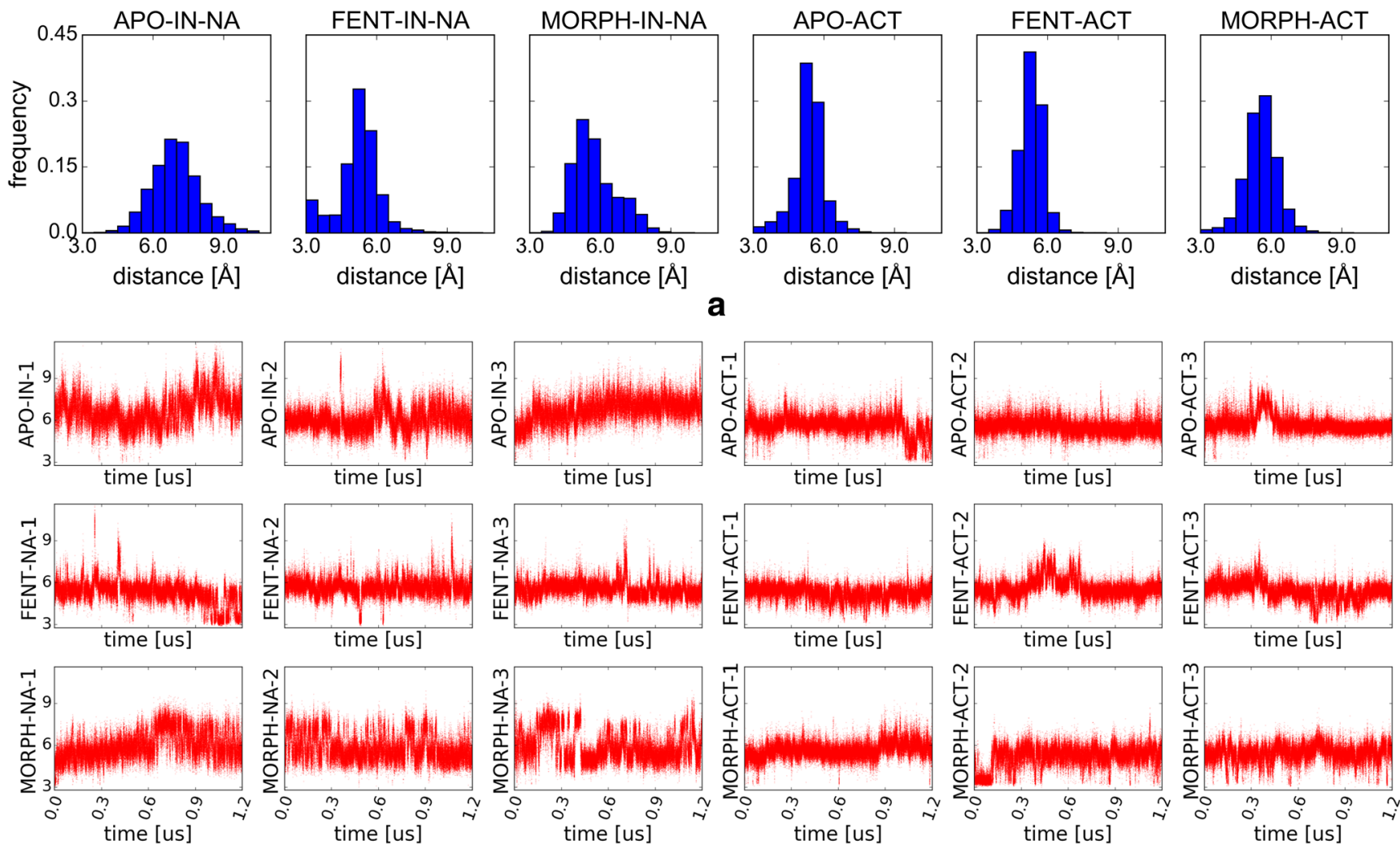

b

Fig. 12 a The distributions of Tyr $326^{7.43}$ O...CG Asp $147^{3.32}$ distance. The histograms are made based on data from the last $300 \mathrm{~ns}$ of three replications (in total $900 \mathrm{~ns}$ ). b The plots showing time evolution of the distance (in $\mathrm{nm}$ ) during $1.2 \mu$ s simulations. Each component picture

demonstrates a separate simulation. The top, middle, and bottom row correspond to APO, FENT, and MORPH, respectively. It seems that time dependencies of the Tyr326 $6^{7.43} \mathrm{O} \ldots \mathrm{CG}$ Asp $147^{3.32}$ distance do not differentiate the APO, FENT, and MORPH systems 

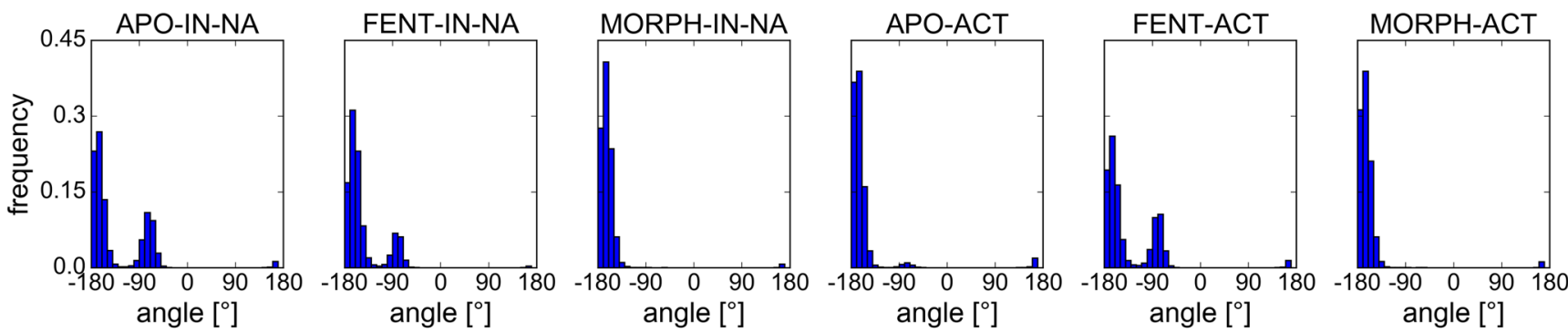

a
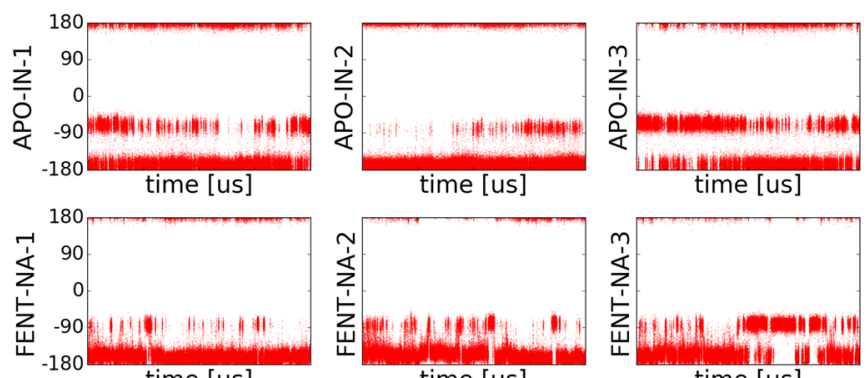

time [us]
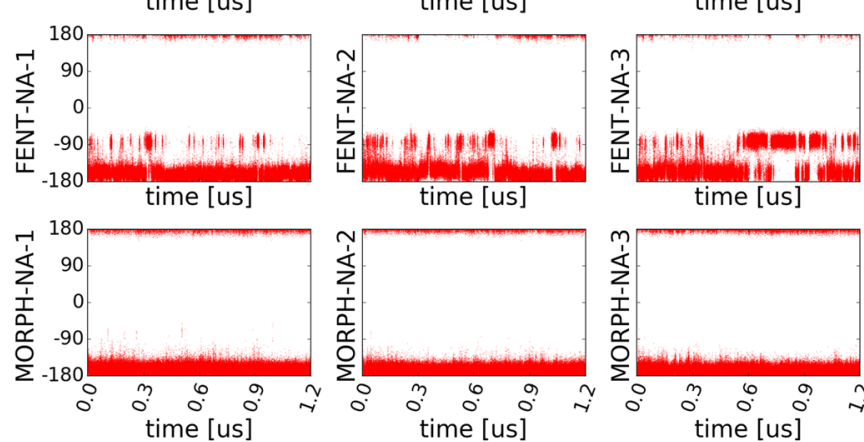

Fig. 13 a The distributions of Asp $147^{3.32} \chi_{1}$ dihedral angle. The histograms are made based on data from the last $300 \mathrm{~ns}$ of three replications (in total $900 \mathrm{~ns}$ ). b The plots showing time dependences of

between APO-IN-NA and MORPH-IN-NA. This could be interpreted that APO-IN-NA runs do not go toward the activation (no $\mathrm{G}$ protein and no agonist present), while in the runs with the agonist it occurs at least partially. Regarding the ACT simulations, $\mathrm{PC} 1$ values are rather concentrated, with only some left-tailing of the APO-ACT. An interpretation for that could be that with the lack of agonist in the binding site, APOACT deactivates faster than the structures with fentanyl or morphine.

The yet clearer clustering within the IN-NA runs is obtained if the second PC is taken into account. PC2 values for FENT-IN-NA group to the higher extremum, while APOIN-NA and MORPH-IN-NA are evenly distributed. The clustering in PC2 values is not so pronounced when ACT simulations are considered. The extraction of the motion associated with PC2 is not easy. However, the clustering could suggest that some receptor elements on the activation pathway inactive-active might be different in the presence of morphine or fentanyl.

To finish, we would like to present a link between the differences in dynamic behavior and the differences in signaling pathway efficacy. The activation mechanism of GPCRs involves the rearrangement of hydrophobic residues below the
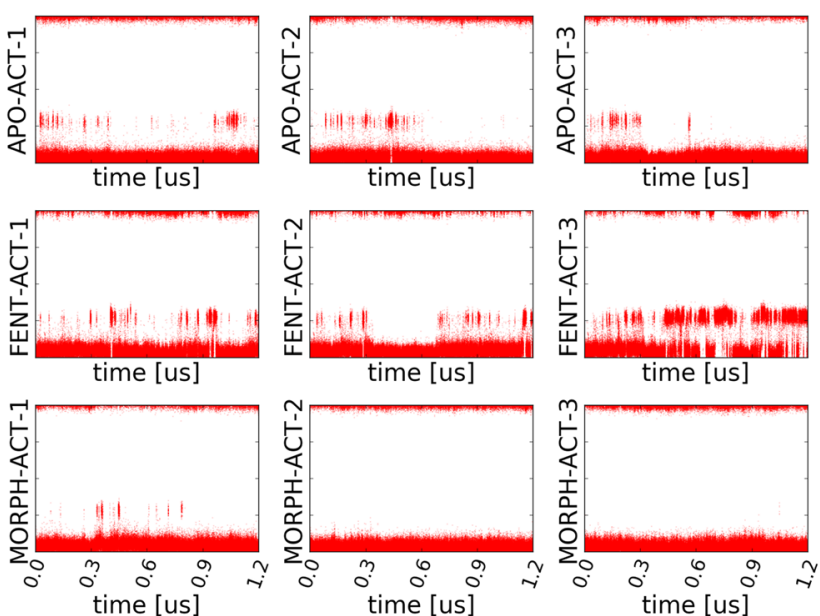

time [us]

time [us]

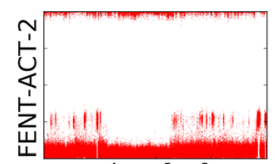

time [us]

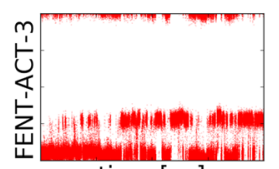

time [us]
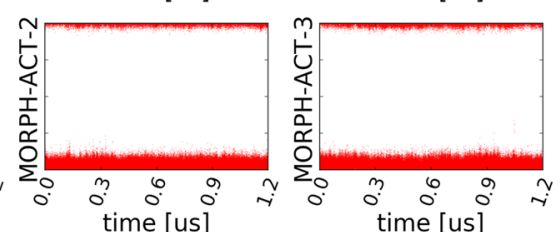

b

the $\chi_{1}$ dihedral angle for Asp147 $7^{3.32}$ during $1.2 \mu$ s simulations. Each component picture demonstrates a separate simulation. The top, middle, and bottom row correspond to APO, FENT, and MORPH, respectively

orthosteric binding pocket ("hydrophobic core"). This rearrangement enables large helical movements that lead to the formation of the water channel from the extracellular to the intracellular side. A residue that connects the ligand binding

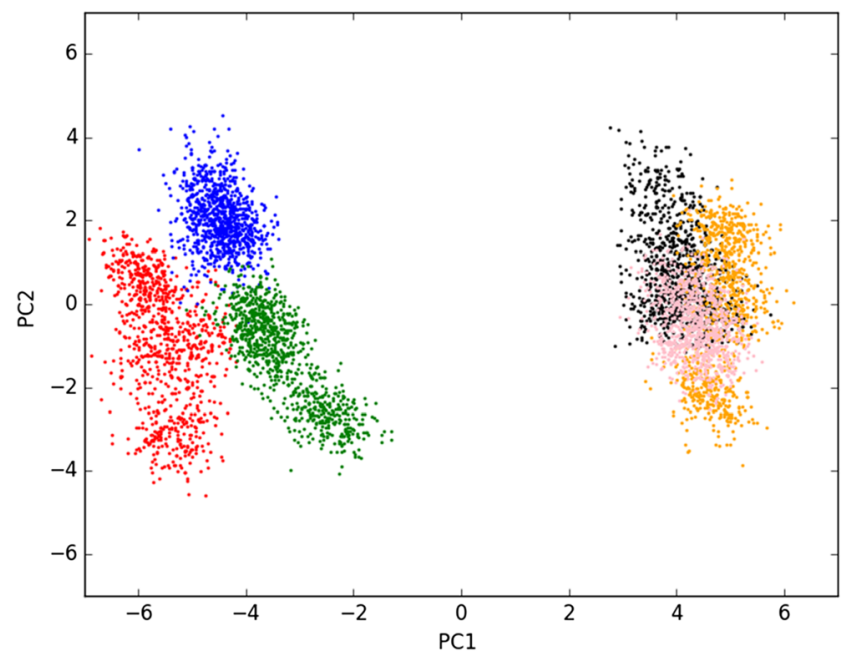

Fig. 14 The plot of the PC2 vs PC1 values. APO-IN-NA (red), FENT-INNA (blue), MORPH-IN-NA (green), APO-ACT (black), FENT-ACT (orange), MORPH-ACT (pink) 
Fig. 15 Superposition of the distributions of: a $\mathrm{PC} 1$ values, $\mathbf{b}$ PC2 values. The histograms are made based on data from the last $300 \mathrm{~ns}$ of three replications (in total $900 \mathrm{~ns}$ )
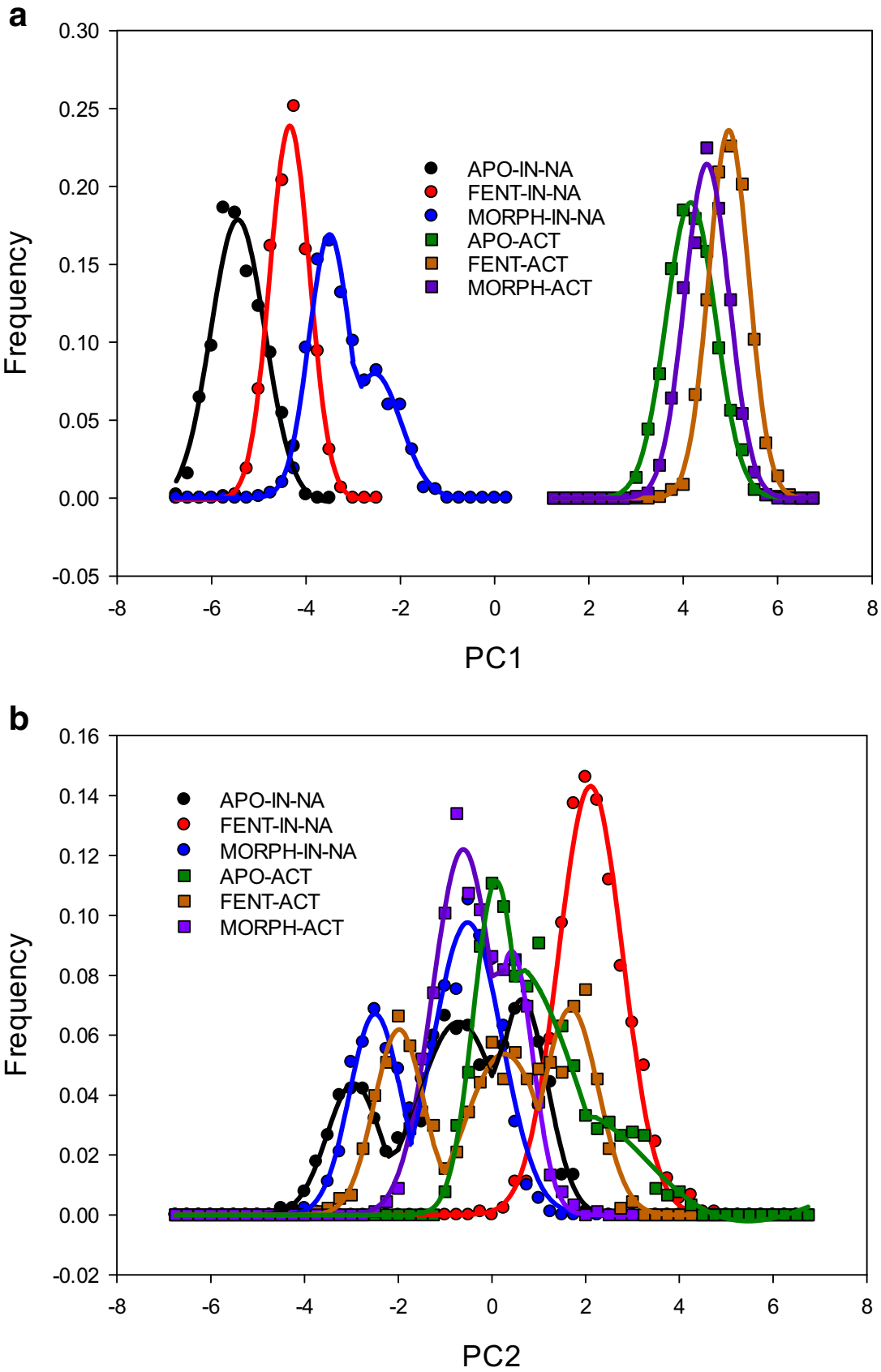

pocket and the hydrophobic core is Trp ${ }^{6.48}$ (highly conserved, Trp or Phe present in over $80 \%$ of GPCR A family proteins). The changes of the rotameric states of this residue have been suggested to form a "microswitch" that participates in the early activation stages by influencing the packing of the hydrophobic core residues and opening a gate for the water influx from the bulk toward the center of the receptor [56]. Presumably, if some agonists stabilize different sets of rotamers of $\operatorname{Trp}^{6.48}$, as is the case in our simulations, it can result in differences in the course of the activation process, yielding different efficacies with regard to binding the intracellular partners.
A similar suggestion could be elucidated for the observed differences in the interaction between Tyr326 7.43 and Asp147 3.32. Tyr326Phe (human receptor numbering) mutations have also been shown to influence opiate receptor bias with yet a different pattern. Tyr $\rightarrow$ Phe exchange disables the ability to form the hydrogen bond between the $\mathrm{Asp}^{3.32}$ and mutated amino acid in TM7, which had been formerly designated as a "3-7 lock". In FENT-INNA simulations the lock seems 'tighter', with either direct $\mathrm{H}$-bond interaction or one mediated by a water molecule happening more often than in APO-IN-NA or MORPHIN-NA. This seems due to the different arrangement of 


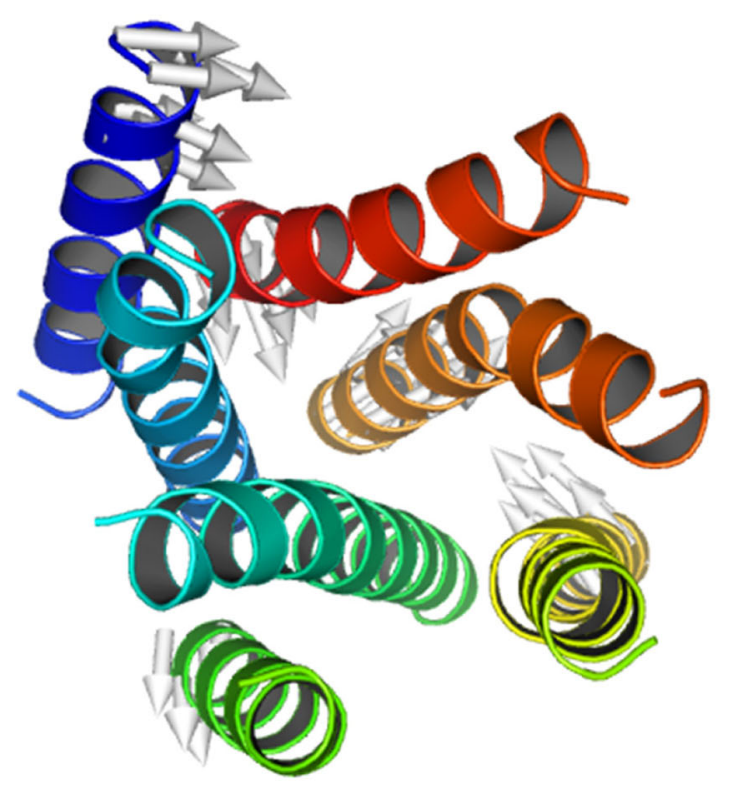

a

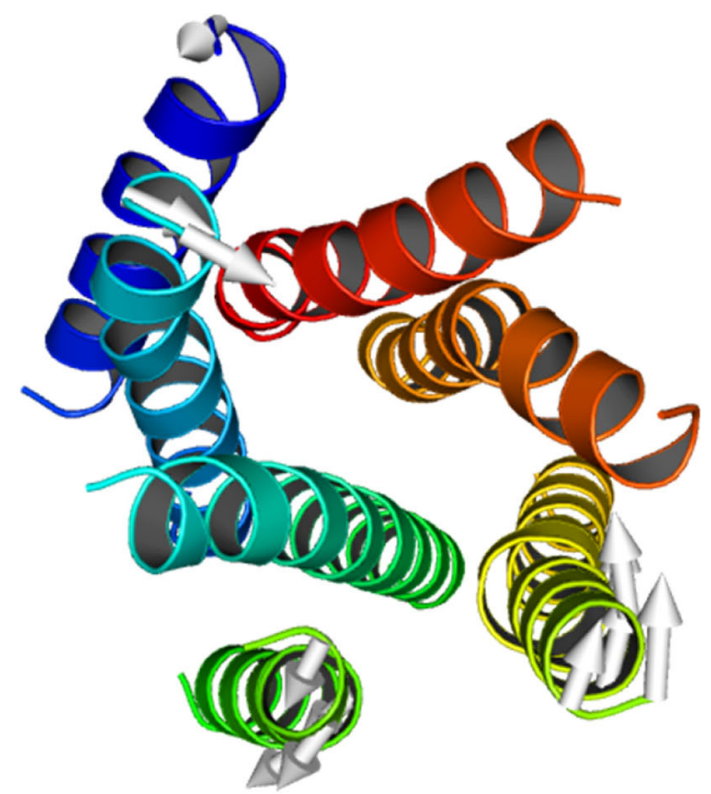

b

Fig. 16 The trajectory projections on the average structure from PCA along: a the PC1, $\mathbf{b}$ the PC2. Helices of the receptor are colored from N-terminal (blue) to C-terminal (red)

fentanyl's piperidine with respect to Asp $147^{3.32}$, as well as a direct interaction of its $\mathrm{N}$-phenethyl with the Tyr326 $6^{7.43}$ aromatic ring.

The question of if and how these differences could lead to structural differences at the intracellular binding site cannot be answered on the basis of the simulations of the timescale presented here. An early hallmark of such possible differences may be different hydration of the allosteric sodium site, which is larger in FENT-IN-NA than MORPH-IN-NA (Fig. 10). More experimental work is necessary to elucidate this hypothesis.

\section{Conclusions}

In the present contribution we describe the molecular dynamics simulations of fentanyl complexed with $\mu \mathrm{OR}$. We performed runs using both inactive and active receptor crystal structures. As a comparison, we also carried out analogous simulations with morphine in the binding site or without a ligand. The main was the study of the ligand-receptor interactions for two ligands. The simulations enabled us to identify fentanyl's binding mode. With both starting points (inactive/active receptor structure), fentanyl converges to a single binding orientation, conforming to some clues stemming from mutagenesis data.

The binding poses of fentanyl and morphine overlap only to a minor extent. The presence of ligands in the binding site is associated with different rotameric states of the $\operatorname{Trp} 293^{6.48}$ residue resulting in different hydration of Asp $114^{2.50}$. Fentanyl also seems to stabilize tighter arrangement of the interaction between Asp147 $7^{3.32}$ and Tyr $326^{7.43}$. Principal component analysis reveals differences in the trajectories dependent on the ligand bound.

We believe that the different extent of communication with receptor helices as well as differences in the Trp293 6.48 rotamers, Asp $147^{3.32}$ and Tyr326 7.43 interaction, and hydration of Asp $114^{2.50}$ observed for fentanyl and morphine in our simulations could be linked to the differences in liganddependent efficacy with respect to receptor intracellular signaling events. The results suggest that small changes in the ligand-residue interactions and the receptor conformations lead to differing efficacies. Further studies of fentanyl derivatives are in progress.

Acknowledgments This work was supported by the National Science Centre Grant No. 2013/11/B/ST4/00785. Calculations were performed under a computational grant no GB65-21 by Interdisciplinary Centre for Mathematical and Computational Modelling (ICM), Warsaw, Poland, and under a computational grant from Świerk Computing Centre, National Centre for Nuclear Research, Warsaw, Poland. Special thanks are due to Professor Sławomir Filipek from the Faculty of Chemistry of the University of Warsaw for his helpful comments and discussions during the project.

Open Access This article is distributed under the terms of the Creative Commons Attribution 4.0 International License (http:// creativecommons.org/licenses/by/4.0/), which permits unrestricted use, distribution, and reproduction in any medium, provided you give appropriate credit to the original author(s) and the source, provide a link to the Creative Commons license, and indicate if changes were made. 


\section{References}

1. Vardanyan RS, Hruby VJ (2014) Fentanyl-related compounds and derivatives: current status and future prospects for pharmaceutical applications. Future Med Chem 6:385-412

2. Gladden RM, Martinez P, Seth P (2016) Centers for Disease Control and Prevention, fentanyl law enforcement submissions and increases in synthetic opioid-involved over dose deaths-27 states, 2013-2014. MMWR Morb Mortal Wkly Rep 65:837-843

3. UNODC (2017) Fentanyl and its analogues-50 years on. UNODC, Global SMART Update. 17:3-11

4. Ellis CR, Kruhlalk NL, Kim MT, Hawkins EG, Stavitskaya L (2014) Predicting opioid receptor binding affinity of pharmacologically unclassified designer substances using molecular docking. PLoS One. https://doi.org/10.1371/journal.pone.0197734

5. Manglik A, Kruse AC (2017) Structural basis for G protein-coupled receptor activation. Biochemistry 56:5628-5634

6. Kaserer T, Lantero A, Schmidhammer H, Spetea M, Schuster D (2016) Receptor: novel antagonists and structural modeling. Sci Rep 6:21548

7. Manglik A, Lin H, Aryal DK, McCorvy JD, Dengler D, Corder G, Levit A, Kling RC, Bernat V, Hübner H, Huang X-P, Sassano MF, Giguère PM, Löber S, Duan D, Scherrer G, Kobilka BK, Gmeiner P, Roth BL, Shoichet BK (2016) Structure-based discovery of opioid analgesics with reduced side effects. Nature 537:185-190

8. Latorraca NR, Venkatakrishnan AJ, Dror RO (2017) GPCR dynamics: structures in motion. Chem Rev 117:139-155

9. Manglik A, Kruse AC, Kobilka TS, Thian FS, Mathiesen JM, Sunahara RK, Pardo L, Weis WI, Kobilka BK, Granier S (2012) Crystal structure of the $\mu$-opioid receptor bound to a morphinan antagonist. Nature 485:321-326

10. Huang W, Manglik A, Venkatakrishnan AJ, Laeremans T, Feinberg EN, Sanborn AL, Kato HE, Livingston KE, Thorsen TS, Kling RC, Granier S, Gmeiner P, Husbands SM, Traynor JR, Weis WI, Steyaert J, Dror RO, Kobilka BK (2015) Structural insights into $\mu$-opioid receptor activation. Nature 524:315-321

11. Koehl A, Hu H, Maeda S, Zhang Y, Qu Q, Paggi JM, Latorraca NR, Hilger D, Dawson R, Matile H, Schertler GFX, Granier S, Weis WI, Dror RO, Manglik A, Skiniotis G, Kobilka BK (2018) Structure of the $\mu$-opioid receptor-Gi protein complex. Nature 558:547-552

12. McCurdy CR, Prisinzano TE (2010) Opioid receptor ligands. In: Abraham DA, Rotella DP (eds) Burger's medicinal chemistry and drug discovery, 7th edn. Wiley, New York, pp 569-735

13. Bick MJ, Greisen PJ, Morey KJ, Antunes MS, La D, Sankaran B, Reymond L, Johnsson K, Medford JI, Baker D (2017) Computational design of environmental sensors for the potent opioid fentanyl. eLife 6:e28909

14. Subramanian G, Paterlini MG, Portoghese PS, Ferguson DM (2000) Molecular docking reveals a novel binding site model for fentanyl at the $\mu$-opioid receptor. J Med Chem 43:381-391

15. Caroll FI, Lewin AH, Mascarella SW, Seltzman HH, Reddy PA (2012) Designer drugs: a medicinal chemistry perspective. Ann N Y Acad Sci 1248:18-38

16. Suzuki J, El-Haddad S (2017) A review: fentanyl and nonpharmaceutical fentanyls. Drug Alcohol Depend 171:107-116

17. Volpe DA, McMahon Tobin GA, Mellon RD, Katki AG, Parker RJ, Colatsky T, Kropp TJ, Verbois SL (2011) Uniform assessment and ranking of opioid mu receptor binding constants for selected opioid drugs. Regul Toxicol Pharmacol 59:385-390

18. Kelly E (2013) Efficacy and ligand bias at the $\mu$-opioid receptor. British J Pharm 169:1430-1446

19. Bremer PT, Kimishima A, Schlosburg JE, Zhou B, Collins KC, Kim D, Janda KD (2016) Combatting synthetic designer opioids: active vaccination ablates lethal doses of fentanyl class drugs. Angew Chem Int Ed 55:3772-3775

20. McPherson J, Rivero G, Baptist M, Llorente J, Al-Sabah S, Krasel C, Dewey WL, Bailey CP, Rosethorne EM, Charlton SJ, Henderson G, Kelly E (2010) $\mu$-Opioid receptors: correlation of agonist efficacy for signaling with ability to activate internalization. Mol Pharmacol 78:756-766

21. Henthorn TK, Liu Y, Mahapatro M, Ng K-Y (1999) Active transport of fentanyl by the blood-brain barrier. J Pharmacol Exp Ther 289:1084-1089

22. Zheng H, Chu J, Zhang Y, Loh HH, Law PY (2011) Modulating $\mu$ opioid receptor phosphorylation switches agonist-dependent signaling as reflected in $\mathrm{PKC} \varepsilon$ activation and dendritic spine stability. $\mathrm{J}$ Biol Chem 286:12724-12733

23. Zuo Z (2005) The role of opioid receptor internalization and $\beta$ arrestins in the development of opioid tolerance. Anesth Analg 101:728-734

24. Zheng H, Loh HH, Law P-Y (2008) $\beta$-Arrestin-dependent $\mu$-opioid receptor-activated extracellular signal-regulated kinases (ERKs) translocate to nucleus in contrast to G protein-dependent ERK activation. Mol Pharmacol 73:178-190

25. Lipiński PFJ, Jarończyk M, Ostrowski S, Dobrowolski JC, Sadlej J (2016) Conformation of six fentanyls revisited. Comput Theor Chem 1086:18-24

26. Došen-Mićović L, Roglić G, Mićović V, Ivanović M (1996) Conformational study of fentanyl and its analogs. 1. Conformational space of the N-phenethyl substituent. Electron $\mathrm{J}$ Theor Chem 1:199-210

27. Došen-Mićović L, Roglić G, Mićović V (2006) Steric interactions and the activity of fentanyl analogs at the $\mu$-opioid receptor. Bioorg Med Chem 14:2887-2895

28. Pogozheva ID, Przydzial MJ, Mosberg HI (2005) Homology modeling of opioid receptor-ligand using experimental constraints. AAPS J 7:E434-E448

29. Trott O, Olson AJ (2010) AutoDock Vina: improving the speed and accuracy of docking with a new scoring function, efficient optimization, and multithreading. J Comput Chem 31:455-461

30. Pil J, Tytgat J (2003) Serine 329 of the $\mu$-opioid receptor interacts differently with agonists. J Pharmacol Exp Ther 304:924-930

31. Ulens C, Van Boven M, Daenens P, Tytgat J (2000) Interaction of $p$ Fluorofentanyl on cloned human opioid receptors and exploration of the role of Trp-318 and His-319 $\mu$-opioid receptor selectivity. J Pharmacol Exp Ther 294:1024-1033

32. Lomize MA, Lomize AL, Pogozheva ID, Mosberg HI (2006) OPM: orientations of proteins in membranes database. Bioinformatics 22:623-625

33. Fiser A, Sali A (2003) ModLoop: automated modeling of loops in protein structures. Bioinformatics 19:2500-2501

34. Frisch MJ, Trucks GW, Schlegel HB, Scuseria GE, Robb MA, Cheeseman JR, Scalmani G, Barone V, Mennucci B, Petersson GA, Nakatsuji H, Caricato M, Li X, Hratchian HP, Izmaylov AF, Bloino J, Zheng G, Sonnenberg JL, Hada M, Ehara M, Toyota K, Fukuda R, Hasegawa J, Ishida M, Nakajima T, Honda Y, Kitao O, Nakai H, Vreven T, Montgomery JA, Peralta JE, Ogliaro F, Bearpark M, Heyd JJ, Brothers E, Kudin KN, Staroverov VN, Keith T, Kobayashi R, Normand J, Raghavachari K, Rendell A, Burant JC, Iyengar SS, Tomasi J, Cossi M, Rega N, Millam NJ, Klene M, Knox JE, Cross JB, Bakken V, Adamo C, Jaramillo J, Gomperts R, Stratmann RE, Yazyev O, Austin AJ, Cammi R, Pomelli C, Ochterski JW, Martin RL, Morokuma K, Zakrzewski VG, Voth GA, Salvador P, Dannenberg JJ, Dapprich S, Daniels AD, Farkas Ö, Foresman JB, Ortiz JV, Cioslowski J, Fox DJ (2013) Gaussian 09, revision D.01. Gaussian, Inc, Wallingford

35. Vanommeslaeghe K, Hatcher E, Acharya C, Kundu S, Zhong S, Shim J, Darian E, Guvench O, Lopes P, Vorobyov I, Mackerell AD (2009) CHARMM general force field: a force field for drug-like 
molecules compatible with the CHARMM all-atom additive biological force fields. J Comput Chem 31:671-690

36. Lee J, Cheng X, Swails JM, Yeom MS, Eastman PK, Lemkul JA, Wei S, Buckner J, Jeong JC, Qi Y, Jo S, Pande VS, Case DA, Brooks CL, MacKerell AD, Klauda JB, Im W (2016) CHARMM-GUI input generator for NAMD, GROMACS, AMBER, OpenMM, and CHARMM/OpenMM simulations using the CHARMM36 additive force field. J Chem Theory Comput 12: 405-413

37. Abraham MJ, Murtola T, Schulz R, Páll S, Smith JC, Hess B, Lindahl E (2015) GROMACS: high performance molecular simulations through multi-level parallelism from laptops to supercomputers. SoftwareX 1:19-25

38. Jo S, Kim T, Im W (2007) Automated builder and database of protein/membrane complexes for molecular dynamics simulations. PLoS One 2:e880

39. Michaud-Agrawal N, Denning EJ, Woolf TB, Beckstein O (2011) MDAnalysis: a toolkit for the analysis of molecular dynamics simulations. J Comput Chem 32:2319-2327

40. Sabbadin D, Ciancetta A, Moro S (2014) Bridging molecular docking to membrane molecular dynamics to investigate GPCRligand recognition: the human $\mathrm{A}_{2} \mathrm{~A}$ adenosine receptor as a key study. J Chem Inf Model 54:169-183

41. Chaturvedi K, Shahrestanifar M, Howells RD (2000) $\mu$ opioid receptor: role for the amino terminus as a determinant of ligand binding affinity. Mol Brain Res 76:64-72

42. Bera I, Laskar A, Ghoshal N (2011) Exploring the structure of opioid receptors with homology modeling based on single and multiple templates and subsequent docking: a comparative study. J Mol Model 17:1207-1221

43. Pasternak GW, Pan Y-X (2013) Mu opioids and their receptors: evolution of a concept. Pharmacol Rev 65:1257-1317

44. Li JG, Chen C, Yin J, Rice K, Zhang Y, Matecka D, de Riel JK, DesJarlais RL, Liu-Chen LY (1999) Asp147 in the third transmembrane Helix of the rat mu opioid receptor forms ion-pairing with morphine and naltrexone. Life Sci 65:175-185

45. Weltrowska G, Chung NN, Lemieux C, Guo J, Lu Y, Wilkes BC, Schiller PW (2010) 'Carba'-analogues of fentanyl are opioid receptor agonists. J Med Chem 53:2875-2881

46. Mansour A, Taylor LP, Fine JL, Thompson RC, Hoversten MT, Mosberg HI, Watson SJ, Akil H (1997) Key residues defining the $\mu$-opioid receptor binding pocket: a site-directed mutagenesis study. J Neurochem 68:344-353

47. Bonner G, Meng F, Akil H (2000) Selectivity of $\mu$-opioid receptor determined by interfacial residues near third extracellular loop. Eur J Pharmacol 403:37-44

48. Perez-Benito L, Doornbos MLJ, Cordomı A, Peeters L, Lavreysen H, Pardo L, Tresadern G (2017) Molecular switches of allosteric modulation of the metabotropic glutamate 2 receptor. Structure 25: $1153-1162$

49. Trzaskowski B, Latek D, Yuan S, Ghoshdastider U, Debinski A, Filipek S (2012) Action of molecular switches in GPCRstheoretical and experimental studies. Curr Med Chem 19:1090 1109

50. Singh R, Hurst BP, Barnett-Norris J, Lynch DL, Reggio PH, Guarnieri F (2002) Activation of the cannabinoid $\mathrm{CB}_{1}$ receptor may involve a W6.48/F3.36 rotamer toggle switch. J Pept Res 60: 357-370

51. McAllister SD, Hurst DP, Barnett-Norris J, Lynch D, Reggio PH, Abood ME (2004) Structural mimicry in class A G protein-coupled receptor rotamer toggle switches: the importance of the F3.36(201)/ W6.48(357) interaction in cannabinoid CB1 receptor activation. J Biol Chem 279:48024-48037

52. Marino KA, Shang Y, Filizola M (2017) Insights into the function of opioid receptors from molecular dynamics simulations of available crystal structures. Br J Pharmacol 175:2834-2845

53. Shang Y, LeRouzic V, Schneider S, Bisignano P, Pasternak GW, Filizola M (2014) Mechanistic insights into the allosteric modulation of opioid receptors by sodium ions. Biochemistry 53:5140 5149

54. Sutcliffe KJ, Henderson G, Kelly E, Sessions RB (2017) Drug binding poses relate structure with efficacy in the mu opioid receptor. J Mol Biol 429:1840-1851

55. Abdi H, Williams LJ (2010) Principal component analysis. Wiley Interdiscip Rev Comput Stat 2:433-459

56. Yuan S, Vogel H, Filipek S (2013) The role of water and sodium ions in the activation of the $\mu$-opioid receptor. Angew Chem Int Ed 52:10112-10115

Publisher's note Springer Nature remains neutral with regard to jurisdictional claims in published maps and institutional affiliations. 